\title{
Event Memory: A Theory of Memory for Laboratory, Autobiographical, and Fictional Events
}

\author{
David C. Rubin \\ Duke University and Aarhus University
}

\author{
Sharda Umanath \\ Duke University
}

\begin{abstract}
An event memory is a mental construction of a scene recalled as a single occurrence. It therefore requires the hippocampus and ventral visual stream needed for all scene construction. The construction need not come with a sense of reliving or be made by a participant in the event, and it can be a summary of occurrences from more than one encoding. The mental construction, or physical rendering, of any scene must be done from a specific location and time; this introduces a "self" located in space and time, which is a necessary, but need not be a sufficient, condition for a sense of reliving. We base our theory on scene construction rather than reliving because this allows the integration of many literatures and because there is more accumulated knowledge about scene construction's phenomenology, behavior, and neural basis. Event memory differs from episodic memory in that it does not conflate the independent dimensions of whether or not a memory is relived, is about the self, is recalled voluntarily, or is based on a single encoding with whether it is recalled as a single occurrence of a scene. Thus, we argue that event memory provides a clearer contrast to semantic memory, which also can be about the self, be recalled voluntarily, and be from a unique encoding; allows for a more comprehensive dimensional account of the structure of explicit memory; and better accounts for laboratory and real-world behavioral and neural results, including those from neuropsychology and neuroimaging, than does episodic memory.
\end{abstract}

Keywords: memory, episodic memory, autobiographical memory, imagery, scenes

Consider the following prototypical event chosen to be consistent with the phenomenological, behavioral, and neural data reviewed in this article: a moment from a family meal that occurs annually at a particular holiday, here Thanksgiving dinner, during the period in which it was held at a particular person's home with the usual people attending, sitting at their usual locations, discussing the usual topics, and being served the usual food. The event is remembered as a single occurrence, even though the year in which it occurred might not be clear and even though aspects of several different Thanksgiving dinners may be combined to form a single instance. Consistent with Tulving's (1985) concept of mental time travel, it might even be the expectation of an occurrence of the meal in the future. We propose a theory to classify and understand memory for such events, as well as for events in typical laboratory episodic memory tasks, and to place them in the broader context of explicit memory.

This article was published Online First October 20, 2014.

David C. Rubin, Department of Psychology and Neuroscience, Duke University, and Center on Autobiographical Memory Research, Aarhus University; Sharda Umanath, Department of Psychology and Neuroscience, Duke University.

Support provided by National Institute of Mental Health Grant R01 MH066079 and Danish National Research Foundation Grant DNRF93. We wish to thank Kaitlyn Batt, Dorthe Berntsen, Annette Bohn, Andrew Butler, Samantha Deffler, Daniel Greenberg, Reed Hunt, Elizabeth Marsh, Katrine Willemoes Rasmussen, Roddy Roediger, Dorthe Thomsen, and John Wixted for comments and suggestions.

Correspondence concerning this article should be addressed to David C. Rubin, Department of Psychology and Neuroscience, Duke University, Box 90086, Durham, NC 27708-0086. E-mail: david.rubin@duke.edu
The Theory

\section{Event Memory}

We define an event memory as the mental construction of a scene, real or imagined, for the past or the future. The scene can be experienced as happening to the person recalling it or imagined as happening to another person. Because a scene cannot be imagined or drawn without an assumed viewpoint, the scene locates the person constructing it relative to other aspects of the scene. Thus, the self enters as a locus in space and time (Neisser, 1988; Skinner, 1972) from which the scene is remembered. A first-person (field) and a third-person (observer) view are egocentric in that both place the person remembering the scene relative to the spatial context of the event (Freud, 1915/1957; Henri \& Henri, 1898; Nigro \& Neisser, 1983). This egocentric perspective from a specific spatial location is what distinguishes event memory from knowledge in phenomenological terms and allows for a sense of reliving (also referred to as autonoetic consciousness, recollection, remembering versus knowing, or mental time travel). The scene may or may not have actions, actors, or emotions as long as its content is sufficient to locate the person recalling it relative to the scene as a whole. We use the term event memory to describe our theoretical construct and use memory for an episode, scene, or event to describe, in neutral theoretical terms, what is remembered.

Event memory does not use a separate memory system for the storage and processing of information; the information needed to recall either an event memory or knowledge is common rather than separate (Mayes, Montaldi, Spencer, \& Roberts, 2004; Palombo, Williams, Abdi, \& Levine, 2013; Rubin, 2006). That is, there is no 
episodic content drawn from an episodic memory system or semantic content drawn from a semantic memory system. Rather, most content used to construct the event is general knowledge (i.e., semantic memory). In Bartlett's (1932, p. 213) terms, remembering "is an imaginative reconstruction, or construction, built out of the relation of our attitude towards a whole active mass of organised past reactions or experience." In particular, the egocentric construction of a scene is most often constructed from general (i.e., allocentric) knowledge of the scene abstracted from exposures to multiple perspectives. The same general information used to generate an event also can be used, with or without a hippocampus, to generate general knowledge (e.g., Maguire, Frackowiak, \& Frith, 1997), such as the allocentric maps of amnesics, to be discussed later.

Both a sense of reliving and a constructed scene are important properties of memories for events. However, for humans, we have accumulated more scientific knowledge about the behavior and neural basis of constructing scenes than about reliving. For other animals, we have no knowledge about reliving. Thus, the change from the traditional focus on reliving allows a more direct integration of the literatures on human memory, visuospatial cognition, and memory across species (e.g., Eichenbaum, 2004; Hassabis \& Maguire, 2007; O'Keefe \& Nadel, 1978; Tolman, 1948; Winocur \& Moscovitch, 2011); diverse theories fall into place in ways that they do not otherwise. At an empirical level, we review studies showing that reliving and constructing a vivid scene of complex events are correlated highly enough to be considered the same empirical measure. We also review the more limited data that suggest that constructing a scene at recall provides the minimum, but not necessarily sufficient, condition for reliving.

At encoding, event memory requires the binding of spatial organization, sensory input, emotions, and other properties to perceive the scene. Thus, at the neural level, at encoding, event memory requires medial temporal lobe structures to "bind" information (Moscovitch, 2008; Squire \& Wixted, 2011) in a detailed fashion (Bonnici et al., 2012; Yonelinas, 2013) as well as other neural structures involved in perceiving the properties of the scene (e.g., Burke et al., 2014; Greenberg \& Rubin, 2003). At retrieval, event memory requires the hippocampus for the construction of the scene (Maguire \& Mullally, 2013) as well as other areas needed for scene construction. A unique time is needed at encoding for the process of binding; however, after similar repeated events are encoded, such unique bindings can be recalled as a single event at retrieval. The time of an event need not be known, either in absolute terms or relative to other events; deciding on when an event occurred is a separate set of processes from recalling other properties of the event (Brewer, 1986, 1996; Eacott \& Easton, 2012; Friedman, 1993, 2004).

\section{Event Memory Contrasted to Episodic Memory and Other Types of Memory for Events}

Event memory and episodic memory attempt to describe memory for events: the fundamental natural kind that is an opposition to knowledge (i.e., semantic memory). They differ in that episodic memory combines several independent dimensions of explicit memory that event memory keeps separate. In Table 1, we list important properties of explicit memory, that is, memory that involves conscious recollection (Graf \& Schacter, 1985). For event memory, these properties can be used in combination to specify any explicit memory; other properties might be added as needed. The properties are at the same level of categorization and are orthogonal in that memories can be found for every possible combination of the properties listed except for reliving, which can occur only for events. Thus they can be seen as the basis of a multidimensional space describing explicit memory in which event versus knowledge is just one dimension. The dimensions have been studied independently, thereby providing evidence about their behavioral and neural properties. Moreover, where the behavioral or neural processes of a dimension are known, they are often different from those of other dimensions; in particular, constructing an event, self-reference, and voluntary versus involuntary recall involve different behavioral systems and neural substrates. Episodic memory, as noted in Table 2, combines several of these properties. Thus, as we expand upon later, dividing explicit memories into episodic and semantic memories provides no clear classification for memories that are recalled as single events but that are imagined from the perspective of a protagonist who is not the person recalling the event, or that are the merging of more than one similar occurrences, or that are recalled without a sense of reliving.

Some of the dimensions in Table 1 are easier to consider as dichotomous, including event memory versus knowledge and involuntary versus voluntary memory. Others are easier to consider as continuous, including having content that is similar to other memories and having intense emotions. Still others can easily be both. For instance, past versus future is a dichotomy that also indicates the remoteness of memories in a continuous fashion, and

Table 1

Important Independent Dimensions of Explicit Memory

1 . Whether the memory is an event memory or knowledge

2. Whether the memory comes with a sense of reliving

3. Whether or not the memory involves the person recalling it

4. The degree to which the memory is similar to other memories and so can rely on content from repeated occurrences

5. Whether, and how far, the constructed event is in the past or the future

6. The degree to which the memory is remembered and judged as a real versus imagined construction (e.g., reality monitoring, what-if scenarios, counterfactuals, accuracy in general)

7. Whether the memory is involuntary or voluntary

8. The degree to which the memory involves intense negative emotions, vivid imagery in various senses, and other factors involved in understanding explicit memory in specific clinical populations

Note. The list is not intended to be exhaustive. Unlike the other properties, whether the memory has a sense of reliving can only be a property of event memory, not of knowledge. 
Table 2

Types of Memories for Events Described in Terms of Important Dimensions

\begin{tabular}{|c|c|c|c|c|c|c|}
\hline Dimension & Event memory & Episodic memory & Neuropsychology & Intrusive memories & $\begin{array}{l}\text { Overgeneral } \\
\text { memories }\end{array}$ & $\begin{array}{l}\text { Nonhuman } \\
\text { episodic-like }\end{array}$ \\
\hline 1. Event memory versus knowledge & Event & Event & - & Event & - & Event \\
\hline 2. Relived or not & - & Relived & - & Relived & - & Unknown \\
\hline 3. About self or not & - & Self & Self & - & Self & - \\
\hline 4. Repeated occurrences & - & Unique & - & Unique & - & Unique \\
\hline 5. Past versus future & - & - & Past & - & - & - \\
\hline 6. Real versus imagined & - & - & Real & Real & Real & Real \\
\hline 7. Voluntary versus involuntary & - & Voluntary & Voluntary & Involuntary & - & Unknown \\
\hline 8. Negative emotions or not & - & - & - & Negative & - & - \\
\hline
\end{tabular}

Note. A dash indicates a particular value is not needed by the concept; thus event memory specifies one dimension, whereas episodic memory specifies five. Some of the choices of properties would change depending on the researcher using the terms. Episodic memory is by Tulving's (1972, 1983, 1984, 1985, 2002) definition, assuming reliving implies an egocentric view. The neuropsychological classifications are based on Butters and Cermak (1986), the Autobiographical Memory Interview (Kopelman et al., 1989), and others. Intrusive memories follow common usage in posttraumatic stress disorder symptoms, and overgeneral memories follow from Williams et al. (2007). Nonhuman episodic-like memory is assumed to be event memory based on the neural involvement of the hippocampus, but lacks phenomenological data.

real versus imagined is a dichotomy that also indicates a continuum of accuracy. The issue of continuous versus dichotomous dimensions is a question we leave open for now, but one that can be addressed empirically.

In Table 2, we use the properties of Table 1 to characterize types of explicit memory that are considered in more detail later in the article. The first two columns contrast event memory with episodic memory as defined by Tulving (1972, 1983, 1984, 1985, 2002) under the assumption that the reliving (i.e., autonoetic consciousness), which is key to episodic memory, requires the scene construction that defines event memory. Episodic memories are event memories accompanied by a sense of reliving, involving the self, for relatively unique experiences, for either the past or the future, that can be judged as real or imagined in a reality monitoring task (Johnson, 1988), and recalled voluntarily in retrieval mode (Tulving, 1983). Being an event memory is just one property that is combined to define episodic memory; being about the self, being a unique occurrence, and being voluntarily recalled can also be true of knowledge, and so we claim that event memory is the simplest, most natural contrast to knowledge.

As shown in Table 2, neuropsychological memories of events often include both event memory and knowledge about the self, for repeated and unique events, in the past, that are judged to be real by the patient, even in confabulations, and are voluntarily recalled, regardless of their emotional content (e.g., Butters \& Cermak, 1986). For instance, the Autobiographical Memory Interview (Kopelman, Wilson, \& Baddeley, 1989) includes both personal semantic and autobiographical scores, but the autobiographical responses can receive the highest rating without any indication that memories are recalled with a sense of reliving or with a constructed scene, thus allowing them to be knowledge from either the perspective of episodic or event memory. For patient care, any form of preserved information related to the self is of practical importance, whereas whether recall includes a sense of reliving or a constructed scene is usually not important. For understanding amnesia, however, these differences matter. As for the remaining columns, in brief, the intrusive memories that are symptoms of posttraumatic stress disorder (PTSD) are event memories involving the self, recalled involuntarily with intense negative emotions. Overgeneral autobiographical memories, in which people do not remember one spe- cific event but rather recall a series or category of events (e.g., parades versus an event at one parade), are often reported in PTSD and depression (Williams, 1996; Williams et al., 2007). Requiring episodic-like memory in nonhumans to be about a unique instance is an added burden not required of laboratory episodic memory or event memory. The differences outlined in Table 2 lead to predictions later in the article.

Two similarities between event and episodic memory should be noted: Neither describes knowledge or semantic memory beyond them being the contrasts for event and episodic memory, and neither makes claims about the need for accuracy. In fact, for event memories, constructing a vivid scene is an effective way to produce false memories (Garry, Manning, Loftus, \& Sherman, 1996) and is part of the phenomenology that led researchers to consider flashbulb memories as accurate when they were not (R. Brown \& Kulik, 1977; Rubin \& Kozin, 1984).

We have now described event memory; the remainder of the article provides support for our claims as outlined in this paragraph. In the abstract and article to this point, we noted three key differences between event memory and episodic memory. We start by providing support for these three differences, each in its own section. First, we replace the sense of reliving, which is a defining feature of episodic memory, with the construction of a scene, because we know next to nothing at the behavioral and neural level about the phenomenological report of reliving but a great deal about the report of having a mental image of a scene. Second, we note that multiple encodings can contribute to the recall of a single scene. By the time a person is old enough to report on a scene or the sense of reliving, there are no truly unique events; rather each new event bears some similarity to past events. Encoding and retrieval are shaped by past similar events, even if recall is thought to be of a single occurrence. Third, both the distinction between memory for an event and for knowledge and the distinction between things done by the self versus by others are crucial to understanding memory, but here we argue that they are different distinctions that should not be conflated. After sections supporting each of these changes, we consider the neural basis of event memory and end the article with individual sections on predictions of the theory and on episodic and autobiographical memory as the theoretical contexts for event memory. 


\section{Replacing a Sense of Reliving With the Mental Construction of a Scene}

\section{The Role of Phenomenology}

As we review in the last section of the article, the early history of the distinction between memory for events and memory for knowledge in philosophy was not based on laboratory experimentation or studies of the neural basis of memory but on the phenomenology of how types of memory differed. A key property was the sense of reliving. It is this sense of reliving that allows mental time travel, of sensing one is part of and can imagine a time other than the present. It motivated and still motivates much of the interest in the distinction between memory for events and knowledge. In addition, like reliving, experiencing a scene from a particular perspective is a phenomenological report. Although we assume the distinction between event memory and knowledge is similar in human and many nonhuman animals, the data for phenomenological properties exist only in humans. We turn next to these two key phenomenological properties of event memory: experiencing a scene from a location and a sense of reliving.

\section{Experiencing a Scene From an Egocentric Perspective}

For memories of events, one needs a "stage on which the remembered event is played or the 'where' for the 'what' to occur in" (Hassabis \& Maguire, 2007, p. 304; see also Knez, 2014; Smith $\&$ Mizumori, 2006). The "stage" must be viewed from a particular seat. The seat need not be on the stage, but it must be in the theater. This introduces an egocentric view even if the knowledge that goes into the construction is based on a more general allocentric map, and even if the egocentric view at recall is one never actually experienced (see also Intraub, 2012).

For a memory to be regarded as "episodic" in nature, that memory must have spatial organization (e.g., Burgess, Becker, King, \& O'Keefe, 2001; Conway, 2009). Similarly, an event memory must have spatial organization; without it, the memory does not have its most basic context and therefore will be judged as knowledge. For a specific event, the layout allows the contents to be organized. "Space provides a critical contextual background for encoding and retrieving episodic memories" (Eichenbaum, Dudchenko, Wood, Shapiro, \& Tanila, 1999, p. 223). Our claim, which can be tested, is that one would judge one's recall to be a memory of an event only if it was experienced as the recall of a scene.

As an example, again consider a memory for a particular Thanksgiving dinner (for similar illustrations, see Brewer, 1986; Eichenbaum, 2004; Linton, 1982). When you attempt to retrieve such a memory, you are probably able to construct a visual image, or at least a sense of the spatial layout of the room from a particular perspective. Many of the details are likely to be drawn from your general knowledge. You may not be able to remember exactly which Thanksgiving it was, what each person wore, or even exactly which people were there. However, it is still an event memory as long as you recall it as a single occurrence and can construct a scene. Perhaps you remember where you sat, who sat next to and across from you, how the room was arranged, and so on. Thus, an event memory can be broken down into a series of associations and details drawn from one's knowledge and orga- nized spatially by the hippocampus and other medial temporal structures (Eichenbaum, 2004; Moscovitch, 2008). However, if you remember who was there and the menu, but you have not constructed a scene of the event, our contention is that you would report recalling the experience as knowledge rather than as a memory for an event, and you would not claim to relive (or recollect or mentally travel in time to) it.

When remembering an event, but not knowledge, a perspective is taken to organize the scene. In practice, people are often not sure of the location from which they are viewing their memory and can change that location, but they agree they are viewing it from some point in space (Berntsen \& Rubin, 2006; Libby, Eibach, \& Gilovich, 2005; Rice, 2010; Rice \& Rubin, 2011). Therefore, whether you are able to conjure a first- or third-person view of the to-beremembered information is one criterion for an event memory; the particular perspective does not matter, only that you have one. Both the event memory and knowledge contain spatial information. However, you can judge from where in space you are viewing the original event in an event memory, but not from where you are viewing the original encoding of knowledge. The construction of the scene also assumes a specific real or imagined time that locates the self in time and allows mental time travel. However, reporting that time requires different processes than constructing the scene (Belli, Bilgen, \& Al Baghal, 2013; Brewer, 1986, 1996; Eacott \& Easton, 2012; Friedman, 1993, 2004; Rubin \& Baddeley, 1989; St. Jacques, Rubin, LaBar, \& Cabeza, 2008).

We claim that the construction and experiencing of a scene requires a particular viewing location; a particular viewing perspective is the only way to mentally construct such a scene or even to physically produce a realistic graphic representation of one. However, this does not imply the storage of scenes. In our Thanksgiving dinner example, the scene could be viewed from a past perspective, such as your usual seat, or from a never-experienced perspective that would have to be constructed from allocentric information, such as from $2 \mathrm{~m}$ above and $3 \mathrm{~m}$ behind your usual seat viewed as if the walls and ceiling that would otherwise block your view were removed. Flexibility and change in the location from which memories are constructed is the rule and often happens over the course of a single autobiographical recall (Rice \& Rubin, 2011). In amnesics, the ability to construct and experience a scene can be lost independent of knowing its components (Hassabis, Kumaran, Vann, \& Maguire, 2007). Traditionally, cognitive psychology has focused on the perception and memory of objects rather than of scenes, but what we normally perceive are scenes. If we are interested in an object, it is almost always imbedded in a scene, and the recall of events is the recall of scenes.

We have argued for the importance of scenes but do not require specific kinds of content. In particular, we do not require an action to be present in the recalled scene of the event. We do this for three reasons. First, we want our claims to apply to the empirical base on which the concept of episodic memory was built: studies of memory in which the events were static words or word pairs, seen once or repeatedly, for a few seconds on a computer screen without action, actors, or plot. Second, we want to be consistent with the observation that a motionless observer contemplating a motionless sublime sunset or a horrific aftermath of destruction can later recall a vivid, emotional, and personally relevant event memory. Third, we want to be consistent with the neuropsychological data in which the concept of event includes any spatially coherent scene 
with or without a central action (Hassabis \& Maguire, 2007). In addition, we do not require a visual image. One can remember a scene of an event that occurred in total darkness, or when blindfolded (Rubin, Burt, \& Fifield, 2003), or if blind (De Beni \& Cornoldi, 1988; Kerr, 1983).

\section{Ratings of the Reliving of Autobiographical Memories}

Reliving helped to motivate the distinction between event memory and knowledge as different ontological categories, and it continues to play a key role in all theories of episodic memory and future episodic thought (D'Argembeau, 2012; Rubin, 2014; Schacter \& Addis, 2007, 2009; Szpunar, 2010; Szpunar, Watson, \& McDermott, 2007). In autobiographical memory research, where what is recalled is almost always a scene, reliving has been measured with two scales. In one, participants rate the extent to which they feel as though they are reliving the original event, and in the other, in line with Wheeler, Stuss, and Tulving (1997), they rate whether they feel that they travel back to the time when it happened, that they are subjects in it again rather than outside observers tied to the present (e.g., Rubin, 2014; Rubin, Boals, \& Berntsen, 2008; Rubin, Dennis, \& Beckham, 2011; Rubin, Schrauf, \& Greenberg, 2003; Rubin \& Siegler, 2004).

In a study that investigated these two scales in detail, 50 undergraduates provided an autobiographical memory to each of 30 cue words, and their ratings were averaged over the 30 cue words for each of 16 scales (Rubin, Schrauf, \& Greenberg, 2003). A correlation matrix based on these average ratings was calculated. This provides a standard between-subjects, individual-differences, or idiographic analysis. Correlations were also calculated within each individual subject based on their ratings of their 30 memories, and these correlations were averaged. This provided the standard nomothetic analysis used in cognitive psychology where the effects are assumed to hold for all subjects. The results were similar for both approaches, though, as Cattell (1952, p. 502) noted, they "have no necessary mathematical relation." For the betweensubjects analyses, reliving correlated most highly with seeing it in my mind (.78), traveling back in time (.76), feeling the same emotions again (.74), and auditory imagery (.69). For the withinsubjects analyses, the average correlations for these variables were $.66, .65, .60$, and .63 . Thus, imagery for the autobiographical memories scenes correlated with reliving as highly as mentally traveling back in time, the second measure of reliving the event. It would have been better to have measures of whether scenes were constructed, but these were not of theoretical interest at the time.

Each of the 1,500 memories ( 50 subjects by 30 cues) was also examined as a separate unit to look for any exceptions to the claim that all highly relived memories had high levels of visual imagery. Of the 521 responses that were rated above 5 on reliving, only eight $(1.5 \%)$ were rated below 5 on visual imagery, where 5 was labeled distinctly on both scales. Of these eight exceptions, six had a rating above 5 for emotions, six had a rating above 5 for setting, and all eight had a rating above 5 for either emotions or setting. Thus, in order to have a high degree of reliving, a high degree of imagery for the scene was present in all but eight cases, and these eight cases all had high ratings on emotions or setting or both.

Over many studies, in both within and between multiple regressions, reliving was predicted by measures of visual imagery, emotion, and audition, with visual imagery typically having the highest correlations (e.g., Rubin, Schrauf, \& Greenberg, 2003; Rubin, Schrauf, Gulgoz, \& Naka, 2007; Rubin \& Siegler, 2004). Ratings of knowing a memory's setting or knowing its spatial layout do not correlate as highly. Similar results occurred for future events with measures of emotional intensity and visua imagery most consistently entering into multiple regressions (Rubin, 2014). Given our current theory, ratings of knowing a memory's setting and its spatial layout should both be divided into ratings of whether the participants constructed a scene, could only provide a name for the location of the setting, or only had allocentric knowledge of the layout.

Reliving is a phenomenological report of a private experience, but neural regions that vary as a function of ratings of reliving can be directly observed with functional magnetic resonance imaging (fMRI). Our lab used 80 words to cue autobiographical memories while participants were in the scanner in a procedure based on the Rubin, Schrauf, and Greenberg (2003) behavioral study just described (Daselaar et al., 2008). For each trial, participants heard a cue word, pressed a button to indicate that they had retrieved a memory, and then elaborated the memory for the remainder of a 24-s period before rating the memory on reliving. Reliving ratings correlated with activity in the period after, but not before, the button press. Areas involved were related to elaborating a scene, including the visual cortex, as well as an area in the right inferior prefrontal gyrus involved in autobiographical memory tasks and in attention to perceptual representation in laboratory memory tasks. Activity in the hippocampus peaked before the button press during memory construction and did not correlate with reliving. The results are consistent with ratings of reliving being metacognitive judgments based on a fully formed memory, which, as the behavioral data indicate, is based heavily on visual imagery of autobiographical scenes.

A sense of reliving similar to that which occurs in autobiographical memory also occurs in déjà vu but with no explicit memory of what one is reliving. It is noteworthy that over several studies, based on both self-reports and analyses of participants' descriptions, the most common trigger of a déjà vu state is the actual physical setting (A. S. Brown, 2004), a finding that parallels our emphasis of the construction of a scene in memory. Overall, the autobiographical memory literature offers strong support for the claim that a visual image of an event is needed for a sense of reliving and that the more vivid the image, the stronger the sense of reliving.

\section{Phenomenological Reports of Remember Versus Know as a Measure of Reliving}

A remember versus know judgment (i.e., R/K) of an explicit memory is often used as synonymous to a judgment of the presence versus absence of a sense of reliving and thus as a way of separating episodic from semantic memories, especially in laboratory recognition memory tasks. We see three main problems with the use of the $R / K$ judgment.

First, R/K may not be terms that anchor a single scale or provide a simple dichotomy (Ingram, Mickes, \& Wixted, 2012; Mickes, Seale-Carlisle, \& Wixted, 2013; Mickes, Wais, \& Wixted, 2009; Wixted \& Mickes, 2010). According to dual-process models in which remember judgments index recollection (i.e., reliving) and know judgments index familiarity, these dimensions should be 
measured independently. Moreover, there is good evidence that as $\mathrm{R} / \mathrm{K}$ judgments are currently used, they may measure the strength of the memory more than they measure whether recollection or familiarity contributes to that strength. That is, remembering may index strong recollection and familiarity, whereas knowing may index weak recollection and familiarity (Wixted \& Mickes, 2010; but see Ingram et al., 2012). This is consistent with findings to be reviewed, that in autobiographical memory, $\mathrm{R} / \mathrm{K}$ correlates with measures of recollection and also with measures of belief in the accuracy of the memory that could be based on familiarity.

Second, we do not know whether R/K judgments are good measures of reliving. R/K was introduced by Tulving (1985) because remembering indicated episodic memory and knowing indicated semantic memory. His laboratory experiments with word pairs and lists of words were consistent with his claim. But they did not examine other interpretations of the results or the usefulness of $\mathrm{R} / \mathrm{K}$ in capturing the essence of his theoretical concepts rather than related concepts. Criticism followed. For instance, Wais, Mickes, and Wixted (2008) concluded:

Our results show that although recollection and familiarity may be different processes, the remember/know paradigm does not probe them directly. As such, dissociations involving remember/know judgments in fMRI studies and in studies involving amnesic patients should not be construed as dissociations between recollection and familiarity. (p. 400)

Similarly, Geraci and colleagues (e.g., Geraci \& McCabe, 2006; Geraci, McCabe, \& Guillory, 2009) demonstrated the importance of explaining the terms remember and know to participants by showing that different explanations produced results that favored contrasting theoretical interpretations. Clearly, participants do not fully intuit Tulving's definitions of these terms.

In autobiographical memory studies that have multiple measures of reliving and belief, $\mathrm{R} / \mathrm{K}$ correlates more highly with belief in the accuracy of the memory than with reliving (e.g., Rubin, Schrauf, \& Greenberg, 2003). For example, Rubin and Siegler (2004) used two ratings of reliving: reliving the original event and traveling back to the time when it happened. They also used four measures of belief in the confidence of the accuracy of the memory including participants' ratings of the degree to which: the memory was an accurate reflection of the event as a neutral observer would report it, they would be willing to testify in court, they could be persuaded that their memory was wrong, and the event in their memory really occurred in the way it was remembered with nothing imagined or fabricated. The scale of $\mathrm{R} / \mathrm{K}$, which asked participants whether they could actually remember occurrences rather than just knowing that it happened, correlated more highly with the belief than the reliving measures. The wording of the $R / K$ scale favored single-process interpretations of $R / K$ as one of confidence or strength; other wordings would be necessary to fully probe this interpretation. Similar collections of rating scales combined with a range of wordings for $\mathrm{R} / \mathrm{K}$ in laboratory studies might help indicate what processes $\mathrm{R} / \mathrm{K}$ is actually measuring in the laboratory.

Third, in addition to these two problems with the $\mathrm{R} / \mathrm{K}$ measure itself, most behavioral and neuroimaging recognition memory studies have an additional limitation for testing event memory. In experiments, independent variables of interest are manipulated and other variables are held constant. During encoding in an $R / K$ experiment, the overall scene is not varied but held constant to the same computer screen viewed from the same location (see Cabeza et al., 2004, for an fMRI approximation). Variations in context usually involve which list the item was on, the task being performed when an item was presented, or at most, the color and location of the word on the computer screen (Ingram et al., 2012). More varied scenes at encoding, such as those had by a rat exploring a maze, would provide more variance for $\mathrm{R} / \mathrm{K}$ judgments to explain and would be needed if $\mathrm{R} / \mathrm{K}$ measures are to be evaluated in terms of event memory, a purpose for which existing studies were not designed.

In summary, in this section, we argued that constructing a scene is necessary for a sense of reliving; that the scene can be constructed from any location, not just the location at encoding; that for the recall of autobiographical memories, where the to-berecalled item is almost always a scene, the vividness of the scene correlates as highly with a sense of reliving as various measures of reliving correlate with each other; and that the current literature on $\mathrm{R} / \mathrm{K}$ does not provide a clear measure of the sense of reliving that can inform event memory. Thus, in terms of phenomenology, it makes sense to replace reliving with scene construction. The section on the neural basis of event memory will provide evidence for preferring scene construction over reliving, if what we know about the behavior and phenomenology of memory for events is to be integrated with what we know about its neural basis.

\section{The Construction of a Single Instance From Knowledge and Repeated Events}

In conventional linguistic terms, an event or episode must occur at one unique time. For Tulving (1972, p. 387), episodic memory contained "personally experienced unique episodes." But, we claim, event memories exist for episodes similar enough to allow for the construction of a single scene at recall. This is because the properties and construction of such repeated events overlap too heavily with those of unique events to be considered fundamentally different from them. There is no theoretical reason to take as a starting assumption that people, or other animals, have fundamentally different mechanisms for constructing and recalling single versus multiple similar events. It seems at least as adaptive to group similar events and note differences among them. Moreover, studies of repeated events support spatial and other schema-based organization (e.g., Bartlett, 1932; Eichenbaum, 2004). Conversely, it is also the case that general knowledge can be acquired from a single experience (Ahn, Brewer, \& Mooney, 1992; Garcia, 1981). Thus, to provide a theory of memory for events that integrates these observations more easily than episodic memory, we allow repeated events recalled as if they were a single instance to be event memories.

Research on event segmentation, especially programmatic research from Zacks and colleagues, provides another perspective on what properties help define events (Dahl, Sonne, Kingo, \& Krøjgaard, 2013; Newtson, \& Engquist, 1976; Zacks, Speer, Swallow, Braver, \& Reynolds, 2007; Zacks \& Swallow, 2007; Zacks \& Tversky, 2001). This research is part of a perception tradition where extraction and use of regularities in the environment, not the type of memory storage, is important. Thus, it is done independently of the properties of episodic, semantic, and event memory. The basic findings are that during perception, event segmentation 
occurs sequentially in real time, dividing a continuous stream of time into a hierarchical organization of event structure with many levels. However, over time, representations of events form in a fairly automatic fashion and are applied to new sequences. That is, experiencing repeated occurrences of a similar event produces a schema that is activated by new similar occurrences and can be used to plan the future and remember past events. Thus, memory organization occurs that supports inferences about a single remembered event. Moreover, it could also support the recall of a single prototype event such as the event in our Thanksgiving dinner example. Also consistent with event memory but not episodic memory, events in the event segmentation literature do not need to be directly observed by the person recalling them but can be reported events that have been read, seen in films, or heard in conversation.

Like the event segmentation literature, the autobiographical memory literature has been concerned and explicit about the issue of repeated events because autobiographical events are not defined by a set paradigm as events are in many laboratory situations. In 1986, Brewer divided memories into those that resulted from a single instance versus those that resulted from repeated or extended instances. He adopted limits on variation similar to what we have for event memory. For Brewer, generic personal memories are of repeated events and come with a sense of reliving. He writes: "I have a generic personal memory of hiking up a mountain in Vermont. I am simply not able to produce a specific personal memory of any particular moment" (Brewer, 1986, p. 30). Brewer also notes that such "memories are constrained by the abstracting properties of the relevant perceptual systems. Thus I can have a generic personal memory of 'going to the beach' ... but not of 'going on vacation"' (p. 30). The same beach example was used later experimentally (e.g., Larsen, 1998; Maguire, VarghaKhadem, \& Hassabis, 2010).

In the laboratory studies, this issue was not ignored; changes in the environment, the internal state of the subject, and the context of the surrounding material were all considered in theories of how the repetition and spacing of individual presentations affected later episodic memory for the occurrence of an item (e.g., Braun \& Rubin, 1998; Glenberg, 1979; Watkins \& Kerkar, 1985). Within the autobiographical memory literature, Barsalou (1988) provided another approach to examining repeated events by extending the concept of basic levels in knowledge (Rosch, Mervis, Gray, Johnson, \& Boyes-Braem, 1976) to events. The basic levels found in concepts, in which the basic level carries more information than levels superordinate and subordinate to it, had already been extended to measure basic levels for environmental scenes (Tversky \& Hemenway, 1983) and activities (Rifkin, 1985). Barsalou expanded this to the construction of events. Such work could be used to inform the limits of combining scenes; however, for this article, we have not explored this possibility but have relied on a person's ability to construct a single spatially organized scene of the repeated events, and like Brewer (1986), we assume that such memories are constrained by the abstracting properties of the relevant perceptual systems.

In order to understand whether recalls were thought to be of repeated events in studies in which participants were asked to recall specific autobiographical memories to cues, our laboratory included the following question among our rating scales: "Is the memory of an event that occurred once at one particular time and place, a summary or merging of many similar or related events, or for events that occurred over a fairly continuous extended period of time lasting more than a day?" From this question we derived a dichotomous once/many scale and a dichotomous merged/extended scale (e.g., Rubin et al., 2008, 2011; Rubin, Schrauf, \& Greenberg, 2003; Rubin \& Siegler, 2004). The question and scales were motivated by the finding that in depression, the recall of autobiographical memory is often overgeneral and that specific events were less likely to be recalled, with merged events dominating memory (for reviews, see Williams, 1996; Williams et al., 2007). For current purposes, these questions offer empirical evidence on differences between event memories that are thought to be of a single event occurring within a day and those we can be fairly certain were not of single events occurring within a day. We typically included 10-20 rating scales in these studies, and the once/many and merged/extended measures were always outliers in that they had much lower correlations with other measures of the memories. Thus, the single versus repeated nature of the event did not affect other properties of the memories. However, in hindsight, we realize that we did not ask whether the memories were recalled as events or as knowledge, overlooking a key distinguishing factor, a point we return to in the section on overgeneral memory in clinical populations.

The strongest theoretical arguments for considering the merging of repeated events as a single event that occurred at one specific time are based on the analysis of a single case from outside the laboratory, but one where accuracy could be measured. Neisser (1981) examined the testimony of John Dean, counsel to President Nixon, to the Senate Watergate Investigation Committee about conversations Dean had with the president. It was later revealed that the actual conversations had been taped. Neisser observed that in general Dean got the gist of the situations correct and told the truth about what was going on broadly, but did not accurately report on specific events. Neisser noted that Dean knew he was to recall only what he was sure happened without added inferences. "Such recall is what Tulving (1972) called episodic; it involves the retrieval of particular autobiographical moments, individual episodes of one's life" (pp. 19-20). Neisser concluded: "He [Dean] believes that he is recalling one conversation at a time, that his memory is 'episodic' in Tulving's sense, but he is mistaken" ( $p$. 20). For Neisser, this is a general property of memory. He compared it to Posner and Keele's (1970) participants who did not recall the stimuli that had been presented as strongly as a prototype of those stimuli that they had not seen. Neisser coined the term repisodic to describe the observation that Dean "is not remembering the 'gist' of a single episode by itself, but the common characteristics of a whole series of events" (p. 20). Many event memories might be like John Dean's in that we believe repeated events to have occurred only once. For others, like our Thanksgiving dinner example, we might suspect that we are combining similar events but still recall it as a single event. Nonetheless, merging aspects of repeated events into the recall of a single event appears to be common and generally unnoticed by both the people remembering events and the psychologists who study them. We address some implications of these ideas in the section on the development and decline of event memory. 


\section{Event Memories That Occur to the Self and to Others}

The distinction between memory for an event and for knowledge and the distinction between things related to the self and to others are different distinctions based on different processes. Unlike episodic memory, event memory does not conflate these distinctions. The sense of reliving is not restricted to "personally experienced unique episodes" (Tulving, 1972, p. 387). People often have reliving for characters with whom they identify or empathize. They can be clear it is not their own life and at the same time experience reliving of other people's memories in the same way Tulving and others allow reliving for imagined future events by imagined future selves. Similarly, people can remember another person's memory as their own (Sheen, Kemp, \& Rubin, 2001). Much of social communication and literature depends upon this ability. In 1988, Larsen, in an article titled "Remembering Without Experiencing: Memory for Reported Events," explored the differences between events experienced by and events reported to the person who recalled them. He noted that "Tulving's definitions left them [reported memories] in no-man's land, outside the taxonomy that came to guide memory research" (Larsen, 1988, p. 331). But as a social, storytelling species (Bruner, 1986), much of the information people have about events is about reported events, and it is important that we can empathize with the protagonist.

The problem with the restriction to personally experienced unique episodes is especially obvious when the episodic-semantic distinction is applied to nonautobiographical fiction. Consider memory for oral traditions (Lord, 1960; Rubin, 1995). The singers often view their recall as the accurate recall of real events that they did not observe but rather had handed down to them orally by authoritative sources. The singer and audience can relive the tale as if they had personally experienced it. There is no "I did," and the tale has often been told in much the same way for centuries. In general, recall of events from an oral tradition, or of any fictional narrative, is not a good fit for semantic or episodic memory. It can be considered semantic memory in that it is the stable shared knowledge of a culture, but it is episodic memory in that the recall is of specific events that are perceived and reacted to as events. Nonetheless, oral traditions exist, have been used for most of human existence to transmit cultural knowledge, and are often remembered with a high degree of reliving. For event memory, such narrative fiction poses no difficulties in categorization; it contains a series of event memories for imaginary events that did not occur to the teller or listener and that have high general knowledge content, especially for the better known tales. Moreover, all stable oral traditions appear to have high visual imagery of scenes (Havelock, 1978) that facilitate event memory. Epics contain regular changes in location, producing series of distinct scenes that limit confusion among and maintain the sequence of actions; the Odyssey is an odyssey. Ballads change location or viewpoint every stanza or two. Some singers of ballads or epics even report that they see the scenes they are singing unfold before them and sing what they see (Rubin, 1995).

\section{The Neural Basis of Event Memory}

We do not postulate a separate neural memory system for the storage of memories for events. Rather, because we assume that event memories are constructed at recall, not stored, we make detailed claims about neural structures in the medial temporal lobes and the visual ventral stream that are needed for the construction and experiencing of scenes. We use the term hippocampus and related structures to include related medial temporal structures, especially the parahippocampal cortex. We avoid specifying the exact anatomical structures involved because they often vary from article to article we review, especially in neuropsychological cases. Some of our claims are supported by recent studies of the hippocampus proper (Yonelinas, 2013), nearby areas including the parahippocampal cortex (Mullally \& Maguire, 2011, 2013), as well as divisions within the hippocampus itself. Here we are proposing a major change in the way long-term explicit memory is considered that has not been used widely in studying the neural basis of behavior. Thus, we are often not in a position to be more specific regarding the role of the exact structures involved.

\section{The Hippocampus and Related Structures}

The hippocampus and related structures in human memory for events. The role of the hippocampus and related structures in memory for events is not controversial. In humans, they are required for memory for events; without them, one cannot encode and, by most accounts, construct detailed memories of events (e.g., Byrne, Becker, \& Burgess, 2007; Eichenbaum, 2004; Hassabis, Kumaran, et al., 2007; Mayes et al., 2004; Moscovitch, 2008; Moscovitch, Nadel, Winocur, Gilboa, \& Rosenbaum, 2006; Squire, 1992; Squire \& Wixted, 2011; Yonelinas, 2013). The ability to create hypothetical events and the ability to remember events are lost together, and they are both lost with bilateral hippocampal damage, according to most (Andelman, Hoofien, Goldberg, Aizenstein, \& Neufeld, 2010; Hassabis, Kumaran, et al., 2007; Race, Keane, \& Verfaellie, 2011; Rosenbaum, Gilboa, Levine, Winocur, \& Moscovitch, 2009; Tulving, 1985) but not all studies (Squire et al., 2010), including studies of developmental amnesia (Cooper, Vargha-Khadem, Gadian, \& Maguire, 2011; Maguire et al., 2010). Whereas most of our claims are for the hippocampus and surrounding areas, several lines of research suggest that the construction of a detailed spatial image of a scene requires the hippocampus proper (for reviews, see Hassabis \& Maguire, 2007; Moscovitch, 2008; Winocur \& Moscovitch, 2011; Yonelinas, 2013).

There are, however, differences among researchers' theories of the function of the hippocampus and related structures in memories for events. Moscovitch, Nadel, Winocur, and colleagues claim that episodic memories, no matter how old or new, are hippocampally dependent for retrieval (Moscovitch, 2008; Nadel, Samsonovich, Ryan, \& Moscovitch, 2000; Rosenbaum, Winocur, \& Moscovitch, 2001; Rosenbaum, Ziegler, Winocur, Grady, \& Moscovitch, 2004; Winocur, Moscovitch, \& Bontempi, 2010). These claims were initially part of the multiple trace theory (Nadel \& Moscovitch, 1997; Nadel et al., 2000; Rosenbaum et al., 2001) in which each encoding was stored as its own trace. Winocur, Moscovitch, and colleagues later introduced the transformation hypothesis, in which, over time, memory for events in the neocortex takes on a more semantic, less detailed nature but the hippocampus is still needed for construction of detailed events (Winocur \& Moscovitch, 2011; Winocur et al., 2010).

In contrast, Squire and others claim older memories become independent of the hippocampus (Scoville \& Milner, 1957; Squire, 1992; Squire \& Alvarez, 1995; Squire \& Zola, 1998). Under this 
theory, the hippocampus will be involved in more detailed memories because recent memories have more details than remote memories due to normal forgetting. Support comes from amnesics with damage restricted to the hippocampus that have intact remote memories for events using R/K judgments (Bayley, Gold, Hopkins, \& Squire, 2005), the Autobiographical Memory Interview (Kopelman et al., 1989; e.g., Reed \& Squire, 1998), and analyses of the memories themselves (Bayley, Hopkins, \& Squire, 2003; Kirwan, Bayley, Galvan, \& Squire, 2008; Reed \& Squire, 1998; Squire et al., 2010). Thus, the neocortex can support remote memories of events without hippocampal involvement (see also the discussion of patients E. P., H. M., K. C., and T. T. in the section on creating scenes versus navigation). Independent of their differences, these researchers emphasize the function of the hippocampus and related structures in memory, especially Squire and colleagues, who view other functions of the hippocampus as derived from their role in the encoding and initial storage of explicit memory (Squire, 1992).

The position that is closest to the one being argued here and that provides the most support for it comes from Maguire and colleagues (e.g., Bonnici et al., 2012; Chadwick, Mullally, \& Maguire, 2013; Hassabis, Kumaran, \& Maguire, 2007; Hassabis, Kumaran, et al., 2007; Hassabis \& Maguire, 2007; Kumaran \& Maguire, 2005; Maguire, Nannery, \& Spiers, 2006). Maguire and colleagues provide much greater precision than we do about the neural structures involved in, and their specific contributions to, scene construction. Their recent exposition of scene construction theory argues that the hippocampus is involved in a range of cognitive functions including episodic memory, imagining, future thinking, and spatial navigation, but this is because these functions all involve scene construction and "the hippocampus is constructing scenes all the time" (Maguire \& Mullally, 2013, p. 1185). In this theory, much like the independent dimensions noted for episodic memory in Table 2, other neural structures serve to support the added dimensions of episodic memory beyond scene construction.

In contrast to these views, Yonelinas (2013) proposes that the hippocampus is not distinguished by its function in memory for events or spatial cognition but rather for higher resolution, detailed processing in attention, perception, memory, and cognitive processes in general. There has been no simple resolution to these differences, as they depend in part on differences in goals, in whether the primary data source is neuropsychological damage or neuroimaging activity, and on definitions. For instance, what Yonelinas considers as evidence for the role of the hippocampus in perception could be identical to what memory theorists consider as the encoding of new memories. For event memory, the function of the hippocampus in the construction of a detailed scene is stressed, a function that is common to many other tasks (Maguire \& Mullally, 2013).

The hippocampus in other species' memory. In the animal literature, the hippocampus is typically associated with spatial processing (e.g., Burgess, Maguire, \& O'Keefe, 2002; Manns \& Eichenbaum, 2009). Place cells that are more active whenever an animal is in a particular location and orientation provide the most direct evidence for this role (O'Keefe \& Dostrovsky, 1971; O'Keefe \& Nadel, 1978). Additionally, lesions to the hippocampus result in spatial deficits (Eichenbaum, 2004; Gaffan, 1994).
However, accumulated evidence that the hippocampus does more than code space is beginning to bridge the gap in function across species (e.g., Corballis, 2013; Eichenbaum, 1999, 2004). For example, the hippocampus is particularly important for relational processing (Eichenbaum, 2004; see also Hassabis \& Maguire, 2007). Building upon Worden's (1992) idea that the hippocampus pieces together fragments into a coherent representation of the environment, Eichenbaum and others suggest that the hippocampus binds multiple disparate inputs (e.g., stimuli, actions, places, context) to create a memorial representation (Cohen \& Eichenbaum, 1993; Eichenbaum, 2004; Smith \& Mizumori, 2006; for comparisons to other theoretical frameworks, see Cohen et al., 1999; Winocur et al., 2010). In line with the human neuropsychological data to be reviewed in the next section, following hippocampal lesions, rats were able to retain a coarse representation of a spatial layout but one that lacked details (Winocur, Moscovitch, Fogel, Rosenbaum, \& Sekeres, 2005; see also Gaffan, 1991, 1994). Unlike human subjects seated in front of the same computer screen for an entire session, rodent subjects are ambulatory and can contribute to a more complete view into how spatial information is acquired and integrated into knowledge and event memory.

At the neuronal level, "the coding of spatial locations by hippocampal place cells emerges from a fundamental representation of behavioral episodes" (Eichenbaum et al., 1999, p. 216). These elements need not all be spatial (Wood, Dudchenko, \& Eichenbaum, 1999), and any bias toward processing spatial information and relationships likely originates as a by-product of the constantly present spatial regularities associated with different event experiences (Eichenbaum, 1999; Eichenbaum et al., 1999; see also Smith \& Mizumori, 2006). Eichenbaum et al. (1999) note that "hippocampal neurons represent the sequence of events that compose ongoing behavioral episodes, and that repeated and related episodic representations can be used to build a memory space in the hippocampus" (p. 215) and "individual hippocampal cells encode regularities present in the animal's every experience, including spatial and non-spatial cues and behavioral actions" (p. 215). Under this view, the hippocampus is not involved in constructing a spatial account of the environment, but an account of important locations similar to what would be needed to construct event memories.

A human analog of space being represented in terms of a history of salient events rather than a more abstract and accurate allocentric map is parodied in the "View of the World from 9th Avenue" (The New Yorker, 1976). This cover provides an egocentric view, in which three city blocks of New York City fill two thirds of the distance to the horizon and contain details of buildings and human activity. The remaining distance to the horizon has six countries and the Pacific Ocean labeled but is nearly empty of details. The direction of each labeled location is good enough for navigation; locations of importance to a New Yorker are emphasized. Actual allocentric human knowledge of the world may not be very different (Tversky, 1993).

Our use of studies of nonhuman hippocampi assumes that at least some animals have episodic-like cognition, but leaves open what properties it shares with human memory for events and how complex it is (e.g., Corballis, 2013; Martin-Ordas, Berntsen, \& Call, 2013; Smith \& Mizumori, 2006). Criteria of episodic memory in animal tests have included whether the memory of an event contains a what, when, and where component (Clayton \& Dickin- 
son, 1999; Clayton, Yu, \& Dickinson, 2001; Knierim, Lee, \& Hargreaves, 2006; Salwiczek, Watanabe, \& Clayton, 2010). More recently, for a number of philosophical and empirical reasons, the when component has been reduced in importance as a criterion for episodic-like memory in nonhuman animals (Corballis, 2013; Eacott \& Easton, 2012; Martin-Ordas et al., 2013), which is consistent with our view. This shift is partly due to the where component increasing in importance, based on lesion data in nonhuman primates (Gaffan, 1991, 1994) and rats (Eacott \& Norman, 2004). Additionally, some evidence shows that rats use spatial cues in order to determine the when component of an event (Ergorul \& Eichenbaum, 2004; see Watson \& Rubin, 1996, for a human analog). In humans, determining when an event occurred is not an integral part of autobiographical memories but a separate cognitive judgment (Belli et al., 2013; Brewer, 1986, 1996; Friedman, 1993, 2004; Rubin \& Baddeley, 1989; St. Jacques et al., 2008). From all perspectives, as stressed by event memory, the when component should be considered separately.

Creating scenes versus navigation. Research already reviewed and other research (e.g., Mayes et al., 2004; Moscovitch, 2008; Moscovitch et al., 2006; Spreng, Mar, \& Kim, 2009) indicate that the hippocampus, as well as structures in the ventral stream, are needed for constructing the detailed scenes that make up event memories. Consistent with event memory, this includes even static scenes; the hippocampus is just as active for static scenes as it is for the recall of particular spatial routes, whereas it is significantly less involved when processing knowledge-based information (Mayes et al., 2004). Detailed mathematical models indicate how longer term allocentric and shorter term egocentric information combine with the location and head position of the observer to account for many details of spatial memory and imagery (Byrne et al., 2007), but for our current level of analysis and purposes, all that is crucial is the observation of hippocampal involvement in scene construction.

Patients with specific hippocampal damage as well as more broad medial temporal damage have been shown to have difficulty with scene discrimination (Lee et al., 2005). When asked to imagine future experiences, amnesics with bilateral hippocampal damage give fragmented descriptions that lack spatial coherence, providing disjointed images rather than a holistic representation that preserve the spatial layout and would indicate the construction of a scene (Hassabis, Kumaran, et al., 2007; Mullally, Hassabis, \& Maguire, 2012; Rasmussen, 2013). These amnesics also scored lower than controls on an experiential index of overall richness of their fictitious imaginings and included fewer spatial, sensory, and emotional details. Importantly for event memory, their constructions were rated as less likely to evoke an image in their mind's eye (see also Maguire et al., 2010, for studies with developmental amnesia, and Raffard, D'Argembeau, Bayard, Boulenger, \& Van der Linden, 2010, for studies with schizophrenia). However, caution is needed in interpreting the rating of imagery and its relation to the rating of reliving. Patients with hippocampal damage are unable to accurately evaluate their memory and future thinking performances, in that their subjective ratings of vividness are either not consistent with objective scores of vividness (Kwan, Carson, Addis, \& Rosenbaum, 2010) or even negatively correlated with them (Addis, Moscovitch, \& McAndrews, 2007). In addition, the phenomenological reports of reliving in patients with neurological damage can be supported by different factors, such as the memory coming more in words when there is visual memory loss (Greenberg, Eacott, Brechin, \& Rubin, 2005).

In contrast, hippocampal damage does not remove all spatial memory or navigation abilities; instead, patients are left with general, coarse, schematic representations that seem to lack rich topographical details (Aly, Ranganath, \& Yonelinas, 2013; Yonelinas, 2013). For example, the patient Tulving studied most, K. C., who despite having widespread damage including and beyond the medial temporal lobes, had some intact spatial memory that was rudimentary and schematic in nature, lacking specific details. K. C. could make allocentric general spatial maps of his neighborhood, but he appeared to lack the details and possibly the ability to construct a scene of a specific event (Rosenbaum et al., 2000). The question for us would be whether he could view the neighborhood as a scene and, in doing so, whether he could place himself at a particular location and thereby introduce himself as an observer of the memory. If not, his spatial memory would be knowledge, not event memory. Squire's patient, E. P., with virtually complete hippocampal damage and broader medial temporal lobe damage (Reed \& Squire, 1998), showed evidence of retaining spatial maps as well (Teng \& Squire, 1999). He was able to describe how he would navigate from his childhood home and between different locations in the area, and even provide alternate routes. Similarly, H. M. could draw a map of his childhood home (Corkin, 2002). Maguire et al. (2006) investigated the spatial memory of London of T. T., a taxi driver, after he sustained bilateral damage that appeared to be restricted to the hippocampi. He had decreased performance in navigation that required detailed spatial layouts rather than general schematics. We know that these patients are amnesic and have trouble recalling the contents of past events and, in some cases, the detailed images needed for event memory of the same locations on which their navigation abilities were tested.

In sum, for event memory, the hippocampus and surrounding areas contribute to binding at encoding and to the construction of detailed visual images at recall; consequently, hippocampal damage results in a lack of event memories. The hippocampus, however, is not needed for memories that are linguistic descriptions of past events, navigation, and other tasks that do not require detailed images. The roles of the hippocampus in spatial cognition and in memory for events are typically discussed separately, but they integrate naturally in event memory. What is often referred to in the animal literature as spatial and context dependent memory and in the human literature as episodic memory also integrates naturally in event memory, though tests of the phenomenological properties of event memory are not possible in nonhuman animals (Fortin, Wright, \& Eichenbaum, 2004; Suzuki \& Clayton, 2000; Winocur et al., 2010). Event memory facilitates these integrations in ways that are not possible with episodic memory.

\section{Visual Areas}

According to event memory, disrupting scene construction anywhere in the brain, not just in the hippocampus and surrounding areas, should disrupt memory for events. If, as we claim, the sense of reliving that is needed for episodic memory depends on scene construction, then episodic memory would make the same prediction.

Evidence from neuropsychology. In our studies that predated the theory of event memory, we had three main hypotheses 
about the effects of visual memory loss on autobiographical memory (Greenberg et al., 2005; Greenberg \& Rubin, 2003; Rubin \& Greenberg, 1998). First, because of the importance of imagery of scenes in autobiographical memory (for a review, see Rubin, 2006), the loss of past visual information would lead to a general loss of autobiographical memory. Second, visual memory loss would cause greater loss of memory for events from before the damage because the information needed to form those memories would be lost, but the processes that bind event memories would still be functioning, producing autobiographical memories using other sensory input after the damage. This is opposite to more severe anterograde amnesia caused by damage to the hippocampus. Third, there is no reason to suspect the visual memories to be temporally organized, so the normal temporal gradients from before the damage should be absent.

We found 11 cases that met the three criteria for visual memory loss devised by Farah (1984). First, the person had to be able to detect, draw, or describe the visual properties of an object that is present, which demonstrates that the deficit could not have arisen from motor, perceptual, linguistic, or general cognitive impairment. Second, the person could not recognize an object on sight alone, by indicating either its name or its function. The third criterion, which defines the deficit as one of long-term visual memory and separates it from cases of associative visual agnosia, is that the person should not be able to draw an object from memory, to describe its visual characteristics from memory, or to detect its visual image upon introspection. All 11 cases with the three criteria of visual memory loss had a general amnesia for memories before and after their damage that extended beyond visual information; the second and third hypotheses were supported to the extent that their case studies allowed us to test them. When the damage was localized, it was often bilateral occipital lobes damage with (in about half the cases) additional damage reported in the inferotemporal region, consistent with damage to the ventral stream of the visual system. In most cases, there was no reported damage to medial temporal structures, and such damage did not appear to have any systematic effects on the symptoms.

There is extreme variation in the ability to have visual images. People without such images and the congenitally and acquired blind are not amnesic and can do many tasks that have been attributed to visual imagery (De Beni \& Cornoldi, 1988; Galton, 1883; Kerr, 1983). Unlike with visual memory deficit patients who by definition are not blind, we assume that the blind have allocentric and egocentric spatial representations but without purely visual information. Detailed tests on the properties of memories for events of these populations are needed.

One of the 11 visual memory deficit patients, M. S., was tested in detail (Greenberg et al., 2005). M. S. had amnesia for both before and after the onset of his visual memory loss, but more severe for before. M. S. was presented with cue words tailored to his life and asked for an autobiographical memory for each. He did ratings for each memory. A correlation matrix among all of the rating scales for his memories before and after the damage was compared to the average within-subject correlations from the undergraduate study discussed earlier (Rubin, Schrauf, \& Greenberg, 2003). The correlations for memories of events that occurred after the damage were much more similar to those of the undergraduates than those from before the damage, indicating that they had more normal integration of sensory and emotional systems. However, these memories had much lower correlations among visual imagery and all other measures, but higher correlations among ratings of the memories coming in words. Thus, the autobiographical memory that was preserved after the damage had verbal descriptions replacing visual imagery.

At the time of these studies, the theory of event memory had not been formulated, and the importance of constructing an image of a scene, as opposed to having visual information, was not appreciated. Farah's third criterion of not being able to detect a visual image, which separated visual memory loss from visual agnosia, meant that scenes could not be experienced and thus, by definition, constituted a loss of event memory. Whether the preserved autobiographical memories from after damage, which have linguistic descriptions but lack visual images, should be considered memory for events or not is a definitional issue, not unlike the controversy surrounding remote memories in amnesiacs.

In contrast to visual memory loss, a review of damage to regions involved in language, narrative, audition, olfaction, and emotion produced the expected functional deficits in their respective systems but was not associated with a general amnesia (Greenberg \& Rubin, 2003). Given our current emphasis on scenes, spatial processing is of special concern. Damage that affected spatial processing, as expected, was mostly in the parietal lobes. There were spatial processing difficulties of various kinds, but they did not affect memory for events. Moreover, they were not accompanied by loss of spatial information in the same way that damage resulting in visual memory deficits caused a loss of visual information. In particular, the parietal lobes seemed to process spatial information but not affect long-term storage for it. For instance, visual neglect patients failed to report information to one side of midline in both perception and memory tasks, but when their orientation was changed, they reported the previously unreported information (Bisiach \& Luzzatti, 1978). Thus, by our account, event memory would still be possible for the parts of scenes they could report. More recent work with patients with parietal damage is consistent with this view. Their memory "deficit was ubiquitous, and not limited to spatial or perceptual aspects of memory. The memory deficit disappeared when memory was specifically probed by asking pointed questions" (Berryhill, Phuong, Picasso, Cabeza, \& Olson, 2007, p. 14415). Thus, the parietal patients do not have a deficit in the processing or long-term storage of information necessary to form a scene. In general, the parietal-based dorsal, or "where," stream of visual processing can be seen as supporting visual control of skilled actions more than conscious perceptual representations of objects and scenes (Milner \& Goodale, 2008).

By considering the results from published reports of 11 individuals with visual memory deficit, examining one of these 11 individuals in detail, and comparing visual loss to loss in other sensory and nonsensory systems, we found that the neuropsychological data supported our earlier hypotheses that visual memory loss would cause greater loss of autobiographical memories than loss in other senses, that the loss would be more severe for memories from before the damage, and that there would be no temporal gradient. This loss of autobiographical memory by definition includes a loss of event memory from both before and after the damage based on the criteria on which the patients were diagnosed. In addition, damage in the parietal lobe, and therefore the dorsal, or "where," stream, is not the cause of visual memory deficit amnesia; damage to the ventral, or "what," stream is. 
The ventral stream. Since the Rubin and Greenberg (1998) article, there have been major advances in understanding the neural basis of the processing of specific kinds of information in specific areas of the ventral stream based on neuroimaging studies (Kanwisher \& Dilks, 2014; Kim \& Biederman, 2011). The first of these areas studied was the fusiform face area (e.g., McCarthy, Puce, Gore, \& Allison, 1997; Puce, Allison, Gore, \& McCarthy, 1995). However, areas processing scenes have now also been studied in detail.

Three scene-related areas in the ventral stream have been identified: the parahippocampal place area, the retrosplenial complex, and the occipital place area (Kanwisher \& Dilks, 2014). In fMRI studies, the parahippocampal place area is activated more by scenes than objects, and its activation to scenes is not affected by removing objects from indoor scenes and leaving just the walls and floor (Epstein \& Kanwisher, 1998). Furthermore, the parahippocampal cortex is active even for "space defining" objects that evoke a strong sense of the surrounding space compared to ones that are "space ambiguous" (Mullally \& Maguire, 2011, 2013). Neuropsychological studies indicate that damage in or near the parahippocampal place area reduces the ability to identify scenes or landmarks (Aguirre \& D'Esposito, 1999; Mendez \& Cherrier, 2003). Patients with such damage can produce maps of places learned before but not after the damage, indicating the parahippocampal place area is for the encoding but not storage of spatial layout (Epstein, DeYoe, Press, Rosen, \& Kanwisher, 2001). The retrosplenial complex is involved in processing spatial layout more than objects, and it appears to play more of a role in navigation than the other two areas (Harel, Kravitz, \& Baker, 2013; Park \& Chun, 2009). The occipital place area is the least well understood of the three areas and anatomically is the earliest in the ventral stream and so may be involved early in the processing of scenes (Dilks, Julian, Paunov, \& Kanwisher, 2013). As research on the ventral stream continues, it should offer insights into the visual system's contribution to event memory.

Evidence from neuroimaging. There is considerable evidence for the role of visual processing in event memory and in autobiographical memory (Burke et al., 2014; for reviews, see McDermott, Szpunar, \& Christ, 2009; Schacter, Addis, \& Buckner, 2007; St. Jacques, 2012). Most relevant for event memory is the effect of a varied egocentric context. A study that addressed this issue directly had participants judge whether a picture they were viewing in the scanner was a novel picture, one they had seen previously on a computer screen in the laboratory, or one they had taken themselves at various locations on their campus (Cabeza et al., 2004). All pictures were of the same scenes, taken from similar perspectives. Thus, the task encourages participants to construct a scene to make their judgment: either the more varied spatial contexts present while taking the pictures or the more monotonous context present while viewing the pictures on the same computer screen. The areas showing greater activity when the picture was taken by the individual included an area in the medial prefrontal cortex associated with self-referential processing, two areas involved in visuospatial processing (the primary visual cortex and cuneus/retrosplenial complex), the hippocampal formation bilaterally, and the right parahippocampal gyrus. The latter regions would all be expected from our discussions of the role of the hippocampus, visual areas, and the ventral stream.

\section{Predictions From Event Memory}

As with any theoretical proposal, a good way to examine the usefulness of the theory of event memory is to formulate predictions. Event memory provides several novel hypotheses that have been previously overlooked, though many are not difficult to test. Some are just questions that have not been considered before. Others are predictions that, if they fail, would point to interesting ways the theory would have to be altered. However, if predictions based on the importance of constructing a scene are not supported, then the theory will have failed; in this section, we make such predictions. One advantage of the way we have conceived of event memory is that many of these hypotheses are created in a rather mechanical way using the properties shown in Table 1.

\section{Neuropsychological Cases of Amnesia}

We start with the clearest example and one that provides many novel predictions for which existing data do not provide good tests. Consider neural damage that results in a loss of memory for events. In contrast to episodic memory, our theory predicts that neural damage to the hippocampus or ventral stream that prevents the construction of scenes should affect event memories whether or not they are relived (Table 1, Property 2), whether or not they are about the person recalling them (Table 1, Property 3 ), whether or not they rely on content that is actually from repeated occurrences (Table 1, Property 4), and whether or not the event memory was recalled voluntarily or involuntarily (Berntsen, 2009, 2010; Berntsen, Staugaard, \& Sørensen, 2013; Hall et al., 2014; Table 1, Property 7). It also predicts that there are other areas that if damaged would affect the individual properties just mentioned but leave the rest of the event memory intact. With frontal lobe damage, some of the same predictions could be made for confabulation. For instance, confabulations should occur whether or not they are relived, are about the person recalling them, rely on content that is from repeated occurrences, or are recalled voluntarily.

These predictions are theoretically interesting and not well studied, though there is nothing to prevent them from being examined. For some of the predictions, there are qualifications that come from the dimensions being studied. For instance, memories that are about the person recalling them may be better recalled. Similarly, from most theoretical perspectives, we might expect less loss in event memories based on repeated occurrences, and so, in less severe amnesias, it would not be surprising to see this result. Other predictions may not be as easy to test.

Making tests along these dimensions for amnesias with different damage and etiologies would advance our theoretical understanding of memory loss; at the least, it would test some currently untested and often unstated implied assumptions. By separating damage that results in loss of event memory or not, distinctions between damage that affects memories about the person recalling them, uniqueness of the event, the past versus future, and involuntary retrieval could be examined to see whether the areas involved are specific to event memory or apply to all explicit memory. For instance, one could ask what types of amnesia show differences depending on whether the memory is about the person remembering it or not. Good evidence exists for the past-future contrast but is lacking otherwise. This may be because one pole of many of these distinctions is part of the definition of episodic 
memory, and thus neuropsychologists using this definition did not ask about these dimensions. In contrast, studies of event memory could demonstrate that, counter to our claims, these distinctions map onto neural regions within the core circuits we proposed for event memory or, consistent with our claims, to regions associated with their more general functions. That is, if patients were found who had difficulty only in event memories that related to themselves and not event memories about others, would this damage be in the core hippocampal and ventral stream areas of event memory or in areas related to self-reference? In addition to testing different etiologies of amnesia, tests of individuals with visual deficits would be informative. For instance, do the qualities of the scenes reported by agnosia patients who do not have visual memory loss, the congenitally and acquired blind, and other individuals affect their sense of reliving and other properties of their memories?

In addition to proposing new predictions, we may be able to address existing controversies; in particular, the nature of remote memories in amnesias in patients with loss to the hippocampus and surrounding areas. As reviewed earlier, both Squire and colleagues and Moscovitch, Nadel, and colleagues agree that the hippocampus is needed for the encoding of events. Both also provide evidence that some remote allocentric spatial information from before the onset of amnesia is spared. Both groups agree that over time memories tend to become less episodic in amnesics and control participants, and neither group is willing to define episodic in terms of patients' reports of reliving. Moreover, both groups agree that the hippocampus is not needed for the recall of memories of remote events that have become semantic. It also appears that both groups would not require hippocampal involvement for memories of events that are recalled as narratives without any accompanying nonlinguistic information. In Squire's case, these claims would also hold for all other remote memories of events in amnesics. Neither group has systematically examined whether the remote memories of amnesics include a scene, that is, an event memory as defined here. However, from the existing data reviewed earlier, it is likely that any memory for an event in amnesia that results from hippocampal damage does not involve a scene. A description of remote memories in amnesics could reduce the scope of the current controversy, especially if it included instruments that have now been used by both groups as well as a thorough description of whether a scene is part of the memory that is modeled on tests used with amnesics by Maguire and Hassabis and colleagues. This is because it is likely that memory for an event is not being defined as closely in the two groups as memory for a scene could be. Event memory would propose that any spared information in the remote memories of amnesics caused by hippocampal or ventral stream damage will not be spatially organized into a scene, though it might have real or confabulated narrative information.

\section{Neuroimaging and Behavioral Studies}

Patients with appropriate behavioral loss are difficult to find, but neuroimaging allows similar tests to be performed with activation instead of loss. We have relied on such evidence in making our claims, but systematic studies varying the dimensions outlined here are lacking. This is in part because they do not follow from the existing definition of episodic memory. Systematic studies such as those varying event memory versus knowledge and either the degree of self-relevance or the uniqueness of the event (Table 1, Properties 1, 3, and 4) would elucidate how these key properties of explicit memory interact.

At a behavioral level, the interpretation of $\mathrm{R} / \mathrm{K}$ judgments has been explored by having participants recall autobiographical events encoded outside the laboratory and provide ratings of $\mathrm{R} / \mathrm{K}$, reliving, and belief in the accuracy of their memories. However, as noted earlier, studies using $\mathrm{R} / \mathrm{K}$ along with other phenomenological reports of belief and reliving do not exist for laboratory studies. Thus, even though it is possible to separate their roles experimentally (Ingram et al., 2012), we still do not know with enough precision what $\mathrm{R} / \mathrm{K}$, in the various ways it is asked, means to participants to use the laboratory data fully in deciding between single- and dual-process theories. In future work, variations in reliving, belief, and other judgments and in $\mathrm{R} / \mathrm{K}$ procedures could be made in experimentally controlled conditions designed to probe contrasting theoretical claims. In addition, varying the spatial context at encoding compared to using only one scene could test whether having varied scenes really does have substantial effects on properties of memories, including reliving.

\section{Overgeneral Memory in Clinical Populations}

Overgeneral memory, in which attempts at recalling autobiographical events produce summarized categories of events rather than single episodes, occurs in many common clinical disorders including PTSD and depression. Therapies attempt to stop the abstract ruminative pattern of thought that accompanies the lack of specific memories, often by using techniques that produce detailed, richer, embodied, or situated memories of events (Williams, 1996; Williams et al., 2007). From the perspective of event memory, there are several unanswered questions, including how often and under what conditions overgeneral memories are event memories versus knowledge and what effect this difference has on the severity of nonmnemonic symptoms. We know of no data at the behavioral level on whether overgeneral memories include scenes, that is, whether they are event memories or knowledge. However, we predict that overgeneral memories that are knowledge, rather than event memories, should be associated with more severe conditions and effects. This is because they would avoid the increased hippocampal and visual system involvement of event memories and thus help avoid potentially negative details. In addition, allowing the independent dimensions from Table 1 that were not allowed under the definition of episodic memory (i.e., whether or not the occurrence happened to the person recalling it and whether or not it relied on content that was actually from repeated occurrences) would also clarify the analysis of overgeneral memories. Overgeneral memories that did not directly involve the participant or that were recalled as a series of event memories should be less related to symptom severity.

Simply asking for ratings such as "Is the memory of an event that occurred once at one particular time and place, a summary or merging of many similar or related events, or for events that occurred over a fairly continuous extended period of time lasting more than a day?" (e.g., Rubin, Schrauf, \& Greenberg, 2003) will no longer be enough to characterize an explicit memory because event memories can be based on repeated events and can be part of an extended series of events. Rather, ratings or other means will be needed to probe if the recall includes a scene. 


\section{The Development and Decline of Event Memory Over the Life Span}

Event memory also allows for a more detailed investigation of the early development of explicit memory. It is unlikely that all the properties associated with explicit memory, including those in Table 1, manifest simultaneously in development. For example, it is possible that knowing whether or not explicit memories are about the person recalling them and whether or not they rely on content that is actually from repeated occurrences develop before the ability to report a sense of reliving. This would reconcile the contradictory claims of requiring a sense of reliving for episodic memory (Tulving, 1983), a property that develops later than other properties of explicit memory (Farrar \& Goodman, 1992; Hudson \& Nelson, 1986; Mandler, 1979), with evidence for the early development of these other properties (e.g., Bauer, 1996; Bauer \& Dow, 1994; Bauer \& Lukowski, 2010; Hudson \& Nelson, 1986; Lechuga, Marcos-Ruiz, \& Bauer, 2001). Moreover, if event memory for repeated events is one of the first kinds of event memory to develop, it is not surprising that researchers have found it very difficult to document early episodic memory, which requires that there be only one exposure. Generally, it seems that children's access to the particular details of events they have experienced is unstable and especially sensitive to the types of retrieval cues used (Arterberry, Milburn, Loza, \& Willert, 2001). Children may have been demonstrating memory for events all along, but according to the definition of episodic memory, these memories may have been erroneously considered as a form of knowledge. In future work, researchers could more pointedly probe children's reports of the presence of a scene to better characterize the form of their memories. Similarly, an entire literature documents younger children's difficulties with reality and source monitoring (Table 1, Property 6; for a review, see Lindsay \& Johnson, 1987). Event memory may help explain children's memory errors in terms of whether memories are remembered as real or imagined. These may be the last aspects of explicit memory to develop. Such investigations may also allow us to more strictly define event memory as opposed to the other aspects of explicit memory tested in the laboratory.

In normal aging, the decline observed in episodic memory may be better characterized by event memory theory, using the properties of explicit memory shown in Table 1 . In the same way that explicit memory as a whole may not manifest simultaneously in early development, its associated properties are not likely to decline at the same rate or even to the same degree in aging. For example, as older adults' ability to remember events declines, it seems that they often show a tendency to rely more heavily on their intact knowledge (Umanath \& Marsh, 2014). In parallel, older adults demonstrate having more generic memories for events, lacking details and often lacking the sense of reliving (Levine, Svoboda, Hay, Winocur, \& Moscovitch, 2002; Piolino et al., 2006; Piolino, Desgranges, \& Eustache, 2009; St. Jacques, Rubin, \& Cabeza, 2012). Drawing on the properties of event memory, we may be able to better characterize whether these memories are knowledge or are still of events. Because older adults are less likely to experience a sense of reliving (Levine et al., 2002; Piolino et al., 2006), just as in early development, older adults' memories for repeated events may be mistaken as knowledge. Probing older adults' reports of these memories for whether or not they experience a scene may provide some insight. More- over, understanding which aspects of event memory, if any, remain relatively stable or decline more slowly with age would allow researchers to create more targeted interventions for memory compensation (e.g., Rubin \& Berntsen, 2009). Such benefits for applied work in improving memory in aging are twofold: first, in understanding which properties require the most support, and second, in devising methods for using those properties that remain to compensate for those that degrade with age.

\section{Episodic and Autobiographical Memory: The Theoretical Contexts for Event Memory}

Throughout Western intellectual history, there has been a tradition of separating memory for events from memory for knowledge, which includes, in chronological order: Aristotle; Augustine; Aquinas; Abercrombie; Brown; Bain; Steele; James; Baker; Wundt; Angell; Bergson; Clarparède; Russell; McDougall; Bentley; Broad; Carr; the Boring, Langfeld, and Weld textbook; Koffka; Schactel; Furlong; Ryle; Ayer; Nielsen; Reiff and Scheerer; Malcolm; Bruner; Pribram; Locke; Langer; Piaget and Inhelder; Brockelman; Penfield; Luria; and of course Tulving (Brewer, 1996; Herrmann, 1982; Tulving, 1983). In this section, we briefly consider episodic and autobiographical memory, the two current dominant approaches to memory for events, and thus the theoretical context in which event memory will need to function.

\section{Episodic Memory}

The current dominant theory of memory for events is Tulving's theory of episodic memory (Tulving, 1972, 1983, 1984, 1985, 2002). Tulving first defined episodic memory as a memory system for information of the form "I did such and such, in such and such a place, at such and such a time" (Tulving, 1972, p. 389). Tulving added to this theory over time, especially in his 1983 book, but he did not change older claims as he did. In his 1985 article, Tulving added the concepts of autonoetic consciousness and mental time travel, which he claimed were defining features of the episodic memory system. In 2002 he added the claim that episodic memory is an ability that only humans display. Tulving's theory introduced and forcefully argued for innovations that were peripheral to, or rejected by, the verbal learning literature of the time. These innovations included a clear distinction between memory that an item had appeared on a list and memory for the stable properties of the items that were not affected by its being on the list, the use of phenomenological reports of private mental events and neuropsychological case studies to bolster his theory, and the development of the idea of the similarity between memories and imagined future events. The phenomenological reports he developed included his concepts of autonoetic consciousness and the distinction between remembering and knowing. These innovations became central to the study of memory and have had a lasting influence. They still define the terms with which memory is discussed and continue to anchor descriptions of memory and our understanding of how it works.

Several early empirical articles challenged Tulving's theory (e.g., Anderson \& Ross 1980; McKoon \& Ratcliff, 1979; Shoben, 
Wescourt, \& Smith, 1978). A formal theoretical critique by McKoon, Ratcliff, and Dell (1986), a response by Tulving (1986), and then a reply by Ratcliff and McKoon (1986) included the difficulty of falsifying Tulving's claims. The most complete set of critiques came in the open peer commentary following Tulving's précis of his 1983 book on episodic memory (Tulving, 1984). While there seemed to be resounding agreement with the heuristic usefulness of the distinction between episodic and semantic memory, described as "intuitively appealing" (Kihlstrom, 1984, p. 243), the idea of distinct systems garnered little favor (e.g., Baddeley, 1984; Lachman \& Naus, 1984; Morton \& Bekerian, 1984; Roediger, 1984; Tiberghien, 1984). Rather, a content-based distinction (e.g., Klatzky, 1984; Wolters, 1984) was preferred.

\footnotetext{
Although Tulving argues for as many as 28 differences between the systems, all but one seems secondary. The primary difference is that episodic memory represents temporally and spatially localized events, while semantic memory represents the abstract or generic information commonly called concepts. (Hintzman, 1984, p. 241)
}

In the context of this history, we have focused on the nature of the content recalled.

Another major critique in the open commentary was that the distinction between semantic and episodic memories is difficult to apply (d'Ydewalle \& Peeters, 1984; Hirst, 1984; Kihlstrom 1984; Lachman \& Naus, 1984; Morton \& Bekerian, 1984; Wolters, 1984). Separating memory into an episodic system for events and a semantic system for knowledge implies different information is stored in each. This criterion is plausible and easier to apply consistently for the well-defined and controlled situation of a list of items. However, in real-world situations, deciding which information would be semantic and which would be episodic became problematic. One recent way to address this problem has been to add new categories of memories in addition to semantic and episodic memory (Renoult, Davidson, Palombo, Moscovitch, \& Levine, 2012). Another way has been to develop coding systems to measure the content of memories and the degree to which they are episodic based on Tulving's definition (e.g., Levine et al., 2002; Palombo et al., 2013). In the context of this history, event memory avoids this problem by assuming that event memory and knowledge are constructed from the same stored information.

In 2002, Tulving still considered episodic memory as "a neurocognitive (brain/mind) system, uniquely different from other memory systems, that enables human beings to remember past experiences" (Tulving, 2002, p. 1), though his view of a system seemed to evolve with the field. The general use of the term memory system had changed, and separate memory systems as originally conceived were no longer the consensus view (e.g., Foster \& Jelicic, 1999; Roediger, Buckner, \& McDermott, 1999; Toth \& Hunt, 1999), a change that has continued (Cabeza \& Moscovitch, 2013; Klein, 2013; Rubin, 2006).

Regardless of critiques, Tulving's theory of episodic and semantic memory systems continues to have a major influence on the entire field of memory research. Memories are still categorized as episodic or semantic, animals are still thought of as having "episodic-like" memory, and reviewers still ask for clarification about whether a task was episodic or semantic.

\section{Autobiographical Memory}

Autobiographical memory is a general term for an area of study encompassing what people can remember of their lives or imagine as occurring in their futures. As used by different researchers, it includes memory for both events and knowledge (Baddeley, 2012; Butters \& Cermak, 1986; Kopelman et al., 1989), memory for events (Rubin, Schrauf, \& Greenberg, 2003; Tulving, 1972), memory for life stories that may contain events and knowledge (Fivush, 2012; Nelson, 1993), and memory for events only when they are embedded in a life story form of organization (Bluck \& Habermas, 2000; Conway, 2009).

For some researchers, knowledge is part of autobiographical memory, and for most researchers, knowledge is needed to organize event memories into a narrative account (Thomsen, 2009). Often that knowledge is autobiographical in that it is specific to one's life or represents general cultural knowledge about expected life events (Berntsen \& Rubin, 2004; Bohn, 2010; Rubin, Berntsen, \& Hutson, 2009). Memories can be organized into a complete life story or life stories of particular periods or chapters of one's life (N. R. Brown, Hansen, Lee, Vanderveen, \& Conrad, 2012; Conway \& Pleydell-Pearce, 2000; Thomsen, 2009; Thomsen, Olesen, Schnieber, Jensen, \& Tønnesvang, 2012). In addition, such memories can be organized in ways to answer questions that require different narrative organization, such as when individuals are asked to report particular things they have done in their current jobs that make them suitable candidates for a new position or when they are asked about the best and worst lectures, annual meetings, or Thanksgiving dinners they have attended (Rubin, 1988, 2012).

Thus, for most theories of autobiographical memory, but not for event memory, narrative is a crucial component. This difference and its relation to definitions of autobiographical memory require consideration here. Bruner (1986) describes the narrative mode of thought as leading to "good stories, gripping drama, believable (though not necessarily 'true') historical accounts. . . . It strives to put its timeless miracles into the particulars of experience, and to locate the experience in time and place" (p. 13). Brewer (1980) defines narrative as "the mental representation of a series of temporally occurring events that are perceived as having a causal or thematic coherence" (p. 223). By these views, narrative, like reliving, is a property of an event or a series of events, not a property of knowledge, though it can make use of knowledge, such as knowledge of general life scripts structuring a particular life story (Berntsen \& Rubin, 2004). Similarly, introducing an egocentric view into a memory, as is required for event memory, can be seen as introducing a minimal narrative. That is, a memory report of a scene, such as "I saw that the dinner table was set in the usual way," is a minimal narrative if it implies a narrator viewing the scene. Such descriptions of scenes can play a crucial role in literary works.

Nevertheless, narrative does not have the empirical support as a defining feature of event memory that a scene does. Key evidence comes from neuropsychology. There are two main neural locations that degrade narrative reasoning: the right hemisphere and the frontal lobes (for reviews, see Greenberg \& Rubin, 2003; Rubin, 2006; Rubin \& Greenberg, 2003). Right hemisphere damage degrades: patients' understanding of stories, especially when goals have to be inferred; patients' appreciation of motives, mood, or emotional tone of characters in stories; and patients' understanding 
of nonliteral statements, jokes, and metaphors. Frontal damage produces confabulations, which can involve event memories. They are often assembled from parts of events that occurred at different times and can include memories of past thoughts that may be recalled as actual events (Greenberg \& Rubin, 2003; Moscovitch, 1989). Neither kind of damage results in a general loss of memories of events. Thus, narrative is a property of memory for events but is not necessary for event memory either by our definition or based on neural areas that if damaged result in a lack of event memories. However, narrative is central to most theories of autobiographical memory. In this context, we have kept event memory and narrative as separate concepts that can contribute to both the recall of an event and series of events.

As shown in Table 1, event memory versus knowledge and whether the memory is about the person recalling it and thus is autobiographical are separate dimensions of explicit memory. The relation of episodic and autobiographical memory is not as simple. Tulving's (1972, p. 389) "I did such and such, in such and such a place, at such and such a time" definition and his claim that episodic memory contained "personally experienced unique episodes" (p. 387) both overlap highly with what is considered autobiographical memory in a way that makes it hard to clearly state how they differ and what their relation might be. In fact, Tulving (1983, p. 28) considers them to refer to the same concept, which solved the problem within his theory but left the distinction in the field where many researchers still contrast episodic and autobiographical memory (e.g., Bluck \& Habermas, 2000; Nelson, 1993). Later attempts at clarifying the relation between autobiographical and episodic memory have not reached any consensus (e.g., Conway, 2009). For us, episodic memory is a type of event memory with the added properties indicated in Table 2, and autobiographical memory is a general term for memories related to the self. The term autobiographical memory is thus free to be defined in a variety of more specific ways by researchers to fit their theoretical needs, not only those discussed in the previous paragraphs but also the neuropsychological, intrusive, and overgeneral memories shown as columns in Table 2, allowing work of understanding autobiographical memory to proceed more efficiently. In this context, event memory is a specific and welldefined concept that can contribute to the understanding of autobiographical memory.

\section{Conclusions}

We offer a new formulation of explicit memory centering on a fundamental difference between event memory and knowledge as different ontological kinds. With a scene recalled as a single event as event memory's defining feature and with other features including those listed in Table 1 as independent dimensions of explicit memory, diverse literatures fall into place in a way that they do not with any other division we could find. Event memory provides a way to probe commonalities in neurocognitive processes among autobiographical, reported, and imagined events as well as events in theater, film, stories, religious rituals, and ceremonies, and thus it has implications beyond memory research. Event memory tries to address many of the accumulated critiques of episodic memory by providing a clear distinction between event memory and memory for knowledge that can become one dimension of the several dimensions that define episodic memory. Overall, we believe event memory better accounts for what we now know about the cognitive and neural basis of memory for events than other theories and hope that it will encourage theoretical debate and empirical research.

\section{References}

Addis, D. R., Moscovitch, M., \& McAndrews, M. P. (2007). Consequences of hippocampal damage across the autobiographical memory network in left temporal lobe epilepsy. Brain, 130, 2327-2342. doi:10.1093/brain/ awm166

Aguirre, G. K., \& D’Esposito, M. (1999). Topographical disorientation: A synthesis and taxonomy. Brain, 122, 1613-1628. doi:10.1093/brain/122 .9 .1613

Ahn, W.-K., Brewer, W. F., \& Mooney, R. J. (1992). Schema acquisition from a single example. Journal of Experimental Psychology: Learning, Memory, and Cognition, 18, 391-412. doi:10.1037/0278-7393.18.2.391

Aly, M., Ranganath, C., \& Yonelinas, A. P. (2013). Detecting changes in scenes: The hippocampus is critical for strength-based perception. $\mathrm{Neu}$ ron, 78, 1127-1137. doi:10.1016/j.neuron.2013.04.018

Andelman, F., Hoofien, D., Goldberg, I., Aizenstein, O., \& Neufeld, M. Y. (2010). Bilateral hippocampal lesion and a selective impairment of the ability for mental time travel. Neurocase, 16, 426-435. doi:10.1080/ 13554791003623318

Anderson, J. R., \& Ross, B. H. (1980). Evidence against a semanticepisodic distinction. Journal of Experimental Psychology: Human Learning and Memory, 6, 441-466. doi:10.1037/0278-7393.6.5.441

Arterberry, M. E., Milburn, M. M., Loza, H. L., \& Willert, A. S. (2001). Retrieval of episodic information from memory: Comparisons among 3 and 4-year-olds, 7- and 8-year-olds, and adults. Journal of Cognition and Development, 2, 283-305. doi:10.1207/S15327647JCD0203_3

Baddeley, A. D. (1984). Neuropsychological evidence and the semantic/ episodic distinction. Behavioral and Brain Sciences, 7, 238-239. doi: 10.1017/S0140525X00044411

Baddeley, A. (2012). Reflections of autobiographical memory. In D. Berntsen \& D. C. Rubin (Eds.), Understanding autobiographical memory: Theories and approaches (pp. 70-88). Cambridge, England: Cambridge University Press. doi:10.1017/CBO9781139021937.007

Barsalou, L. W. (1988). The content and organization of autobiographical memories. In U. Neisser (Ed.), Remembering reconsidered: Ecological and traditional approaches to the study of memory (pp. 193243). New York, NY: Cambridge University Press. doi:10.1017/ CBO9780511664014.009

Bartlett, F. C. (1932). Remembering: A study in experimental and social psychology. Cambridge, England: Cambridge University Press.

Bauer, P. J. (1996). What do infants recall of their lives? Memory for specific events by one- to two-year-olds. American Psychologist, 51, 29-41. doi:10.1037/0003-066X.51.1.29

Bauer, P. J., \& Dow, G. A. (1994). Episodic memory in 16- and 20-monthold children: Specifics are generalized but not forgotten. Developmental Psychology, 30, 403-417. doi:10.1037/0012-1649.30.3.403

Bauer, P. J., \& Lukowski, A. F. (2010). The memory is in the details: Relations between memory for the specific features of events and long-term recall during infancy. Journal of Experimental Child Psychology, 107, 1-14. doi:10.1016/j.jecp.2010.04.004

Bayley, P. J., Gold, J. J., Hopkins, R. O., \& Squire, L. R. (2005). The neuroanatomy of remote memory. Neuron, 46, 799-810. doi:10.1016/j .neuron.2005.04.034

Bayley, P. J., Hopkins, R. O., \& Squire, L. R. (2003). Successful recollection of remote autobiographical memories by amnesic patients with medial temporal love lesions. Neuron, 38, 135-144. doi:10.1016/S08966273(03)00156-9 
Belli, R. F., Bilgen, I., \& Al Baghal, T. (2013). Memory, communication, and data quality in calendar interviews. Public Opinion Quarterly, 77, 194-219. doi:10.1093/poq/nfs099

Berntsen, D. (2010). The unbidden past: Involuntary autobiographical memories as a basic mode of remembering. Current Directions in Psychological Science, 19, 138-142. doi:10.1177/0963721410370301

Berntsen, D. (2009). Involuntary autobiographical memories. An introduction to the unbidden past. Cambridge, England: Cambridge University Press. doi:10.1017/CBO9780511575921

Berntsen, D., \& Rubin, D. C. (2004). Cultural life scripts structure recall from autobiographical memory. Memory \& Cognition, 32, 427-442. doi:10.3758/BF03195836

Berntsen, D., \& Rubin, D. C. (2006). Emotion and vantage point in autobiographical memory. Cognition \& Emotion, 20, 1193-1215. doi: 10.1080/02699930500371190

Berntsen, D., Staugaard, S. R., \& Sørensen, L. M. T. (2013). Why am I remembering this now? Predicting the occurrence of involuntary (spontaneous) episodic memories. Journal of Experimental Psychology: General, 142, 426-444. doi:10.1037/a0029128

Berryhill, M. E., Phuong, L., Picasso, L., Cabeza, R., \& Olson, I. R. (2007). Parietal lobe and episodic memory: Bilateral damage causes impaired free recall of autobiographical memory. Journal of Neuroscience, 27, 14415-14423. doi:10.1523/JNEUROSCI.4163-07.2007

Bisiach, E., \& Luzzatti, C. (1978). Unilateral neglect of representational space. Cortex, 14, 129-133.

Bluck, S., \& Habermas, T. (2000). The life story schema. Motivation and Emotion, 24, 121-147. doi:10.1023/A:1005615331901

Bohn, A. (2010). Generational differences in cultural life scripts and life story memories of younger and older adults. Applied Cognitive Psychology, 24, 1324-1345. doi:10.1002/acp.1641

Bonnici, H. M., Kumaran, D., Chadwick, M. J., Weiskopf, N., Hassabis, D., \& Maguire, E. A. (2012). Decoding representations of scenes in the medial temporal lobes. Hippocampus, 22, 1143-1153. doi:10.1002/hipo .20960

Braun, K., \& Rubin, D. C. (1998). The spacing effect depends on an encoding deficit, retrieval, and time in working memory: Evidence from once-presented words. Memory, 6, 37-65. doi:10.1080/741941599

Brewer, W. F. (1980). Literary theory, rhetoric, stylistics: Implications for psychology. In R. J. Spiro, B. C. Bruce, \& W. F. Brewer (Eds.), Theoretical issues in reading comprehension (pp. 221-239). Hillsdale, NJ: Erlbaum.

Brewer, W. F. (1986). What is autobiographical memory? In D. C. Rubin (Ed.), Autobiographical memory (pp. 25-49). Cambridge, England: Cambridge University Press. doi:10.1017/CBO9780511558313.006

Brewer, W. F. (1996). What is recollective memory? In D. C. Rubin (Ed.), Remembering our past: Studies in autobiographical memory (pp. 1966). Cambridge, England: Cambridge University Press. doi:10.1017/ CBO9780511527913.002

Brown, A. S. (2004). The déjà vu experience. New York, NY: Psychology Press.

Brown, N. R., Hansen, T. G. B., Lee, P. J., Vanderveen, S. A., \& Conrad, F. G. (2012). Historically defined autobiographical periods: Their origins and implications. In D. Berntsen \& D. C. Rubin (Eds.), Understanding autobiographical memory, Theories and approaches (pp. 160180). Cambridge, England: Cambridge University Press. doi:10.1017/ CBO9781139021937.013

Brown, R., \& Kulik, J. (1977). Flashbulb memories. Cognition, 5, 73-99. doi:10.1016/0010-0277(77)90018-X

Bruner, J. (1986). Actual minds, possible worlds. Cambridge, MA: Harvard University Press.

Burgess, N., Becker, S., King, J. A., \& O'Keefe, J. (2001). Memory for events and their spatial context: Models and experiments. Philosophical Transactions of the Royal Society of London Series B: Biological Sciences, 356, 1493-1503. doi:10.1098/rstb.2001.0948
Burgess, N., Maguire, E. A., \& O'Keefe, J. (2002). The human hippocampus and spatial and episodic memory. Neuron, 35, 625-641. doi 10.1016/S0896-6273(02)00830-9

Burke, J. F., Long, N. M., Zaghloul, K. A., Sharan, A. D., Sperling, M. R. \& Kahana, M. J. (2014). Human intracranial high-frequency activity maps episodic memory formation in space and time. Neurolmage, 85 , 834-843. doi:10.1016/j.neuroimage.2013.06.067

Butters, N., \& Cermak, L. S. (1986). A case study of the forgetting of autobiographical knowledge: Implications for the study of retrograde amnesia. In D. C. Rubin (Ed.), Autobiographical memory (pp. 253-272). Cambridge, England: Cambridge University Press. doi:10.1017/ CBO9780511558313.021

Byrne, P., Becker, S., \& Burgess, N. (2007). Remembering the past and imagining the future: A neural model of spatial memory and imagery. Psychological Review, 114, 2, 340-375. doi:10.1037/0033-295X.114.2 .340

Cabeza, R., \& Moscovitch, M. (2013). Memory systems, processing modes, and components: Functional neuroimaging evidence. Perspectives on Psychological Science, 8, 49-55. doi:10.1177/1745691612469033

Cabeza, R., Prince, S. E., Daselaar, S. M., Greenberg, D. L., Budde, M., Dolcos, F., . . . Rubin, D. C. (2004). Brain activity during episodic retrieval of autobiographical and laboratory events: An fMRI study using a novel photo paradigm. Journal of Cognitive Neuroscience, 16, 1583-1594. doi:10.1162/0898929042568578

Cattell, R. B. (1952). The three basic factor-analytic designs: Their interrelations and derivatives. Psychological Bulletin, 49, 499-520. doi: $10.1037 / \mathrm{h} 0054245$

Chadwick, M. J., Mullally, S. L., \& Maguire, E. A. (2013). The hippocampus extrapolates beyond the view in scenes: An fMRI study of boundary extension. Cortex, 49, 2067-2079. doi:10.1016/j.cortex.2012.11.010

Clayton, N. S., \& Dickinson, A. (1999). Scrub jays (Aphelocoma coerulescens) remember the relative time of caching as well as the location and content of their caches. Journal of Comparative Psychology, 113, 403416. doi:10.1037/0735-7036.113.4.403

Clayton, N. S., Yu, K. S., \& Dickinson, A. (2001). Scrub jays (Aphelocoma coerulescens) form integrated memories of the multiple features of caching episodes. Journal of Experimental Psychology: Animal Behavior Processes, 27, 17-29. doi:10.1037/0097-7403.27.1.17

Cohen, N. J., \& Eichenbaum, H. (1993). Memory, amnesia, and the hippocampal system. Cambridge, Massachusetts: MIT Press.

Cohen, N. J., Ryan, J., Hunt, C., Romine, L., Wszalek, T., \& Nash, C. (1999). Hippocampal system and declarative (relational) memory: Summarizing the data from functional neuroimaging studies. Hippocampus, 9, 83-98. doi:10.1002/(SICI)1098-1063(1999)9:1<83::AID-HIPO9>3 $.0 . \mathrm{CO} ; 2-7$

Conway, M. A. (2009). Episodic memories. Neuropsychologia, 47, 2305 2313. doi:10.1016/j.neuropsychologia.2009.02.003

Conway, M. A., \& Pleydell-Pearce, C. W. (2000). The construction of autobiographical memories in the self-memory system. Psychological Review, 107, 261-288. doi:10.1037/0033-295X.107.2.261

Cooper, J. M., Vargha-Khadem, F., Gadian, D. G., \& Maguire, E. A (2011). The effect of hippocampal damage in children on recalling the past and imagining new experiences. Neuropsychologia, 49, 1843-1850. doi:10.1016/j.neuropsychologia.2011.03.008

Corballis, M. C. (2013). Mental time travel: A case for evolutionary continuity. Trends in Cognitive Sciences, 17, 5-6. doi:10.1016/j.tics 2012.10.009

Corkin, S. (2002). What's new with the amnesic patient H. M.? Nature Reviews Neuroscience, 3, 153-160. doi:10.1038/nrn726

Dahl, J. J., Sonne, T., Kingo, O. S., \& Krøjgaard, P. (2013). On the development of episodic memory: Two basic questions. Nordic Psychology, 65, 189-207. doi:10.1080/19012276.2013.807661

D'Argembeau, A. (2012). Autobiographical memory and future thinking. 
In D. Berntsen \& D. C. Rubin (Eds.), Understanding autobiographical memory: Theories and approaches (pp. 311-330). Cambridge, England: Cambridge University Press. doi:10.1017/CBO9781139021937.022

Daselaar, S. M., Rice, H. J., Greenberg, D. L., Cabeza, R., LaBar, K. S., \& Rubin, D. C. (2008). The spatiotemporal dynamics of autobiographical memory: Neural correlates of recall, emotional intensity, and reliving. Cerebral Cortex, 18, 217-229. doi:10.1093/cercor/bhm048

De Beni, R., \& Cornoldi, C. (1988). Imagery limitations in totally congenitally blind subjects. Journal of Experimental Psychology: Learning, Memory, and Cognition, 14, 650-655. doi:10.1037/0278-7393.14.4.650

Dilks, D. D., Julian, J. B., Paunov, A. M., \& Kanwisher, N. (2013). The occipital place area is causally and selectively involved in scene perception. Journal of Neuroscience, 33, 1331-1336. doi:10.1523/ JNEUROSCI.4081-12.2013

d'Ydewalle, G., \& Peeters, R. (1984). There is more going on in the human mind. Behavioral and Brain Sciences, 7, 239-240. doi:10.1017/ S0140525X00044423

Eacott, M. J., \& Easton, A. (2012). Remembering the past and thinking about the future: Is it really about time? Learning and Motivation, 43, 200-208. doi:10.1016/j.lmot.2012.05.012

Eacott, M. J., \& Norman, G. (2004). Integrated memory for object, place, and context in rats: A possible model of episodic-like memory? Journal of Neuroscience, 24, 1948-1953. doi:10.1523/JNEUROSCI.2975-03 .2004

Eichenbaum, H. (1999). The hippocampus and mechanisms of declarative memory. Behavioural Brain Research, 103, 123-133. doi:10.1016/ S0166-4328(99)00044-3

Eichenbaum, H. (2004). Hippocampus: Cognitive processes and neural representations that underlie declarative memory. Neuron, 44, 109-120. doi:10.1016/j.neuron.2004.08.028

Eichenbaum, H., Dudchenko, P., Wood, E., Shapiro, M., \& Tanila, H. (1999). The hippocampus, memory, and place cells: Is it spatial memory or a memory space? Neuron, 23, 209-226. doi:10.1016/S08966273(00)80773-4

Epstein, R., DeYoe, E. A., Press, D. Z., Rosen, A. C., \& Kanwisher, N. (2001). Neuropsychological evidence for a topographical learning mechanism in parahippocampal cortex. Cognitive Neuropsychology, 18, 481508. doi:10.1080/02643290125929

Epstein, R., \& Kanwisher, N. (1998). A cortical representation of the local visual environment. Nature, 392, 598-601. doi:10.1038/33402

Ergorul, C., \& Eichenbaum, H. (2004). The hippocampus and memory for "what," "where," and "when." Learning \& Memory, 11, 397-405. doi: $10.1101 / 1 \mathrm{~m} .73304$

Farah, M. J. (1984). The neurological basis of mental imagery: A componential analysis. Cognition, 18, 245-272. doi:10.1016/00100277(84)90026-X

Farrar, M. J., \& Goodman, G. S. (1992). Developmental changes in event memory. Child Development, 63, 173-187. doi:10.2307/1130911

Fivush, R. (2012). Subjective perspective and personal timeline in the development of autobiographical memory. In D. Berntsen \& D. C. Rubin (Eds.), Understanding autobiographical memory: Theories and approaches (pp. 226-245). Cambridge, England: Cambridge University Press. doi:10.1017/CBO9781139021937.017

Fortin, N. J., Wright, S. P., \& Eichenbaum, H. (2004). Recollection-like memory retrieval in rats is dependent on the hippocampus. Nature, 431, 188-191. doi:10.1038/nature02853

Foster, J. K., \& Jelicic, M. (Eds.). (1999). Memory: Systems, process or function? New York, NY: Oxford University Press. doi:10.1093/acprof: oso/9780198524069.001.0001

Freud, S. (1957). Repression. In C. M. Baines \& J. Strachey (Eds. \& Trans.), The standard edition of the complete psychological works of Sigmund Freud (Vol. 14, pp. 146-158). London, England: Hogarth Press. (Original work published 1915)
Friedman, W. J. (1993). Memory for the time of past events. Psychological Bulletin, 113, 44-66. doi:10.1037/0033-2909.113.1.44

Friedman, W. J. (2004). Time in autobiographical memory. Social Cognition, 22, 591-605. doi:10.1521/soco.22.5.591.50766

Gaffan, D. (1991). Spatial organization of episodic memory. Hippocampus, 1, 262-264. doi:10.1002/hipo.450010311

Gaffan, D. (1994). Scene-specific memory for objects: A model of episodic memory impairment in monkeys with fornix transection. Journal of Cognitive Neuroscience, 6, 305-320. doi:10.1162/jocn.1994.6.4.305

Galton, F. (1883). Inquiries into the human faculty and its development. London, England: Macmillan. doi:10.1037/14178-000

Garcia, J. (1981). Tilting at the windmills of academe. American Psychologist, 36, 149-158. doi:10.1037/0003-066X.36.2.149

Garry, M., Manning, C. G., Loftus, E. F., \& Sherman, S. J. (1996). Imagination inflation: Imagining a childhood event inflates confidence that it occurred. Psychonomic Bulletin \& Review, 3, 208-214. doi: 10.3758/BF03212420

Geraci, L., \& McCabe, D. P. (2006). Examining the basis for illusory recollection: The role of remember/know instructions. Psychonomic Bulletin \& Review, 13, 466-473. doi:10.3758/BF03193871

Geraci, L., McCabe, D. P., \& Guillory, J. J. (2009). On interpreting the relationship between remember-know judgments and confidence: The role of instructions. Consciousness and Cognition, 18, 701-709. doi: 10.1016/j.concog.2009.04.010

Glenberg, A. M. (1979). Component-levels theory of the effects of spacing of repetitions on recall and recognition. Memory \& Cognition, 7, 95112. doi:10.3758/BF03197590

Graf, P., \& Schacter, D. L. (1985). Implicit and explicit memory for new associations in normal and amnesic subjects. Journal of Experimental Psychology: Learning, Memory, and Cognition, 11, 501-518. doi: 10.1037/0278-7393.11.3.501

Greenberg, D. L., Eacott, M. J., Brechin, D., \& Rubin, D. C. (2005). Visual memory loss and autobiographical amnesia: A case study. Neuropsychologia, 43, 1493-1502. doi:10.1016/j.neuropsychologia.2004.12.009

Greenberg, D. L., \& Rubin, D. C. (2003). The neuropsychology of autobiographical memory. Cortex, 39, 687-728. doi:10.1016/S00109452(08)70860-8

Hall, S. A., Rubin, D. C., Miles, A., Davis, S. W., Wing, E. A., Cabeza, R., \& Berntsen, D. (2014). The neural basis of involuntary episodic memories. Journal of Cognitive Neuroscience. Advance online publication. doi:10.1162/jocn_a_00633

Harel, A., Kravitz, D. J., \& Baker, C. I. (2013). Deconstructing visual scenes in cortex: Gradients of object and spatial layout information. Cerebral Cortex, 23, 947-957. doi:10.1093/cercor/bhs091

Hassabis, D., Kumaran, D., \& Maguire, E. (2007). Using imagination to understand the neural basis of episodic memory. Journal of Neuroscience, 27, 14365-14374. doi:10.1523/JNEUROSCI.4549-07.2007

Hassabis, D., Kumaran, D., Vann, S., \& Maguire, E. (2007). Patients with hippocampal amnesia cannot imagine new experiences. Proceedings of the National Academy of Sciences of the United States of America, 104, 1726-1731. doi:10.1073/pnas.0610561104

Hassabis, D., \& Maguire, E. (2007). Deconstructing episodic memory with construction. Trends in Cognitive Sciences, 11, 299-306. doi:10.1016/ j.tics.2007.05.001

Havelock, E. A. (1978). The Greek concept of justice: From its shadow in Homer to its substance in Plato. Cambridge, MA: Harvard University Press. doi:10.4159/harvard.9780674183513

Henri, V., \& Henri, C. (1898). Earliest recollections. Popular Science Monthly, 53, 108-115.

Herrmann, D. J. (1982). The semantic-episodic distinction and the history of long-term memory typologies. Bulletin of the Psychonomic Society, 20, 207-210. doi:10.3758/BF03334817 
Hintzman, D. L. (1984). Episodic versus semantic memory: A distinction whose time has come-and gone? Behavioral and Brain Sciences, 7, 240-241. doi:10.1017/S0140525X00044435

Hirst, W. (1984). Factual memory? Behavioral and Brain Sciences, 7, 241-242. doi:10.1017/S0140525X00044447

Hudson, J., \& Nelson, K. (1986). Repeated encounters of a similar kind: Effects of familiarity on children's autobiographic memory. Cognitive Development, 1, 253-271. doi:10.1016/S0885-2014(86)80004-1

Ingram, K. M., Mickes, L., \& Wixted, J. T. (2012). Recollection can be weak and familiarity can be strong. Journal of Experimental Psychology: Learning, Memory, and Cognition, 38, 325-339. doi:10.1037/ a0025483

Intraub, H. (2012). Rethinking visual scene perception. Wiley Interdisciplinary Reviews: Cognitive Science, 3, 117-127. doi:10.1002/wcs.149

Johnson, M. K. (1988). Reality monitoring: An experimental phenomenological approach. Journal of Experimental Psychology: General, 117, 390-394. doi:10.1037/0096-3445.117.4.390

Kanwisher, N., \& Dilks, D. D. (2014). The functional organization of the ventral visual pathway in humans. In J. S. Werner \& L. M. Chalupa (Eds.), The new visual neurosciences (pp. 733-746). Cambridge, MA: MIT Press.

Kerr, N. H. (1983). The role of vision in "visual imagery" experiments: Evidence from the congenitally blind. Journal of Experimental Psychology: General, 112, 265-277. doi:10.1037/0096-3445.112.2.265

Kihlstrom, J. F. (1984). A fact is a fact is a fact. Behavioral and Brain Sciences, 7, 243-244. doi:10.1017/S0140525X00044460

Kim, J. G., \& Biederman, I. (2011). Where do objects become scenes? Cerebral Cortex, 21, 1738-1746. doi:10.1093/cercor/bhq240

Kirwan, C. B., Bayley, P. J., Galvan, V. V., \& Squire, L. R. (2008). Detailed recollection of remote autobiographical memory after damage to the medial temporal lobe. Proceedings of the National Academy of Sciences of the United States of America, 105, 2676-2680. doi:10.1073/ pnas.0712155105

Klatzky, R. L. (1984). Armchair theorists have more fun. Behavioral and Brain Sciences, 7, 244. doi:10.1017/S0140525X00044472

Klein, S. B. (2013). Making the case that episodic recollection is attributable to operations occurring at retrieval rather than to content stored in a dedicated subsystem of long-term memory. Frontiers in Behavioral Neuroscience, 7, 3. doi:10.3389/fnbeh.2013.00003

Knez, I. (2014). Place and the self: An autobiographical memory synthesis. Philosophical Psychology, 27, 164-192. doi:10.1080/09515089.2012 .728124

Knierim, J. J., Lee, I., \& Hargreaves, E. L. (2006). Hippocampal place cells: Parallel input streams, subregional processing, and implications for episodic memory. Hippocampus, 16, 755-764. doi:10.1002/hipo .20203

Kopelman, M. D., Wilson, B. A., \& Baddeley, A. D. (1989). The Autobiographical Memory Interview: A new assessment of autobiographical and personal semantic memory in amnesic patients. Journal of Clinical and Experimental Neuropsychology, 11, 724-744. doi:10.1080/ 01688638908400928

Kumaran, D., \& Maguire, E. (2005). The human hippocampus: Cognitive maps or relational memory? Journal of Neuroscience, 25, 7254-7259. doi:10.1523/JNEUROSCI.1103-05.2005

Kwan, D., Carson, N., Addis, D. R., \& Rosenbaum, R. S. (2010). Deficits in past remembering extend to future imagining in a case of developmental amnesia. Neuropsychologia, 48, 3179-3186. doi:10.1016/j .neuropsychologia.2010.06.011

Lachman, R., \& Naus, M. J. (1984). The episodic/semantic continuum in an evolved machine. Behavioral and Brain Sciences, 7, 244-246. doi: 10.1017/S0140525X00044484

Larsen, S. F. (1988). Remembering without experiencing: Memory for reported events. In U. Neisser \& E. Winograd (Eds.), Remembering reconsidered: Ecological and traditional approaches to the study of memory (pp. 326-355). Cambridge, England: Cambridge University Press.

Larsen, S. F. (1998). What is it like to remember? On the phenomenal qualities of memory. In C. P. Thompson, D. J. Herrmann, D. Bruce, J. D. Read, D. G. Payne, \& M. P. Toglia (Eds.), Autobiographical memory: Theoretical and applied perspectives (pp. 163-190). Mahwah, NJ: Erlbaum.

Lechuga, M. T., Marcos-Ruiz, R., \& Bauer, P. J. (2001). Episodic recall of specifics and generalization coexist in 25-month-old children. Memory, 9, 117-132. doi:10.1080/09658210042000111

Lee, A. C., Buckley, M. J., Pegman, S. J., Spiers, H., Scahill, V. L., Gaffan, D., . . Hodges, J. R. (2005). Specialization in the medial temporal lobe for processing of objects and scenes. Hippocampus, 15, 782-797. doi: 10.1002/hipo.20101

Levine, B., Svoboda, E., Hay, J. F., Winocur, G., \& Moscovitch, M (2002). Aging and autobiographical memory: Dissociating episodic from semantic retrieval. Psychology and Aging, 17, 677-689. doi: 10.1037/0882-7974.17.4.677

Libby, L. K., Eibach, R. P., \& Gilovich, T. (2005). Here's looking at me The effect of memory perspective on assessments of personal change. Journal of Personality and Social Psychology, 88, 50-62. doi:10.1037/ 0022-3514.88.1.50

Lindsay, D. S., \& Johnson, M. K. (1987). Reality monitoring and suggestibility: Children's ability to discriminate among memories from different sources. In S. J. Ceci, M. P. Toglia, \& D. F. Ross (Eds.), Children's eyewitness memory (pp. 92-121). New York, NY: Springer. doi 10.1007/978-1-4684-6338-5_6

Linton, M. (1982). Transformations of memory in everyday life. In U. Neisser (Ed.), Memory observed: Remembering in natural contexts (pp. 107-118). San Francisco, CA: Freeman.

Lord, A. B. (1960). The singer of tales. Cambridge, MA: Harvard University Press.

Maguire, E. A., Frackowiak, R. S., \& Frith, C. D. (1997). Recalling routes around London: Activation of the right hippocampus in taxi drivers Journal of Neuroscience, 17, 7103-7110.

Maguire, E. A., \& Mullally, S. L. (2013). The hippocampus: A manifesto for change. Journal of Experimental Psychology: General, 142, 11801189. doi: $10.1037 / \mathrm{a} 0033650$

Maguire, E. A., Nannery, R., \& Spiers, H. J. (2006). Navigation around London by a taxi driver with bilateral hippocampal lesions. Brain, 129, 2894-2907. doi:10.1093/brain/awl286

Maguire, E. A., Vargha-Khadem, F., \& Hassabis, D. (2010). Imagining fictitious and future experiences: Evidence from developmental amnesia Neuropsychologia, 48, 3187-3192. doi:10.1016/j.neuropsychologia .2010 .06 .037

Mandler, J. M. (1979). Categorical and schematic organization in memory. In C. R. Puff (Ed.), Memory organization and structure (pp. 259-296). New York, NY: Academic Press.

Manns, J. R., \& Eichenbaum, H. (2009). A cognitive map for object memory in the hippocampus. Learning \& Memory, 16, 616-624. doi 10.1101/lm.1484509

Martin-Ordas, G., Berntsen, D., \& Call, J. (2013). Memory for distant past events in chimpanzees and orangutans. Current Biology, 23, 1438-1441. doi:10.1016/j.cub.2013.06.017

Mayes, A. R., Montaldi, D., Spencer, T. J., \& Roberts, N. (2004). Recalling spatial information as a component of recently and remotely acquired episodic or semantic memories: An fMRI study. Neuropsychology, 18, 426-441. doi:10.1037/0894-4105.18.3.426

McCarthy, G., Puce, A., Gore, J. C., \& Allison, T. (1997). Face-specific processing in the human fusiform gyrus. Journal of Cognitive Neuroscience, 9, 605-610. doi:10.1162/jocn.1997.9.5.605

McDermott, K. B., Szpunar, K. K., \& Christ, S. E. (2009). Laboratorybased and autobiographical retrieval tasks differ substantially in their 
neural substrates. Neuropsychologia, 47, 2290-2298. doi:10.1016/j .neuropsychologia.2008.12.025

McKoon, G., \& Ratcliff, R. (1979). Priming in episodic and semantic memory. Journal of Verbal Learning and Verbal Behavior, 18, 463480. doi:10.1016/S0022-5371(79)90255-X

McKoon, G., Ratcliff, R., \& Dell, G. S. (1986). A critical evaluation of the semantic-episodic distinction. Journal of Experimental Psychology: Learning, Memory, and Cognition, 12, 295-306. doi:10.1037/0278-7393 .12 .2 .295

Mendez, M. F., \& Cherrier, M. M. (2003). Agnosia for scenes in topographagnosia. Neuropsychologia, 41, 1387-1395. doi:10.1016/S00283932(03)00041-1

Mickes, L., Seale-Carlisle, T. M., \& Wixted, J. T. (2013). Rethinking familiarity: Remember/know judgments in free recall. Journal of Memory and Language, 68, 333-349. doi:10.1016/j.jml.2013.01.001

Mickes, L., Wais, P. E., \& Wixted, J. T. (2009). Recollection is a continuous process: Implications for dual process theories of recognition memory. Psychological Science, 20, 509-515. doi:10.1111/j.1467-9280 .2009.02324.x

Milner, A. D., \& Goodale, M. A. (2008). Two visual systems re-viewed. Neuropsychologia, 46, 774-785. doi:10.1016/j.neuropsychologia.2007 .10 .005

Morton, J., \& Bekerian, D. A. (1984). The episodic/semantic distinction: Something worth arguing about. Behavioral and Brain Sciences, 7, 247-248. doi:10.1017/S0140525X00044514

Moscovitch, M. (1989). Confabulation and the frontal systems. In H. L. Roediger III, \& F. I. M. Craik (Eds.), Varieties of memory and consciousness: Essays in honour of Endel Tulving (pp. 133-160). Hillsdale, NJ: Erlbaum.

Moscovitch, M. (2008). The hippocampus as a "stupid," domain-specific module: Implications for theories of recent and remote memory, and of imagination. Canadian Journal of Experimental Psychology, 62, 62-79. doi:10.1037/1196-1961.62.1.62

Moscovitch, M., Nadel, L., Winocur, G., Gilboa, A., \& Rosenbaum, R. (2006). The cognitive neuroscience of remote episodic, semantic and spatial memory. Current Opinion in Neurobiology, 16, 179-190. doi: 10.1016/j.conb.2006.03.013

Mullally, S. L., Hassabis, D., \& Maguire, E. A. (2012). Scene construction in amnesia: An fMRI study. Journal of Neuroscience, 32, 5646-5653. doi:10.1523/JNEUROSCI.5522-11.2012

Mullally, S. L., \& Maguire, E. A. (2011). A new role for the parahippocampal cortex in representing space. Journal of Neuroscience, 31, 7441-7449. doi:10.1523/JNEUROSCI.0267-11.2011

Mullally, S. L., \& Maguire, E. A. (2013). Exploring the role of spacedefining objects in constructing and maintaining imagine scenes. Brain and Cognition, 82, 100-107. doi:10.1016/j.bandc.2013.02.013

Nadel, L., \& Moscovitch, M. (1997). Memory consolidation, retrograde amnesia and the hippocampal complex. Current Opinion in Neurobiology, 7, 217-227. doi:10.1016/S0959-4388(97)80010-4

Nadel, L., Samsonovich, A., Ryan, L., \& Moscovitch, M. (2000). Multiple trace theory of human memory: Computational, neuroimaging, and neuropsychological results. Hippocampus, 10, 352-368. doi:10.1002/ 1098-1063(2000) 10:4<352::AID-HIPO2>3.0.CO;2-D

Neisser, U. (1981). John Dean's memory: A case study. Cognition, 9, 1-22. doi:10.1016/0010-0277(81)90011-1

Neisser, U. (1988). Five kinds of self-knowledge. Philosophical Psychology, 1, 35-59. doi:10.1080/09515088808572924

Nelson, K. (1993). The psychological and social origins of autobiographical memory. Psychological Science, 4, 7-14. doi:10.1111/j.1467-9280 .1993.tb00548.x

Newtson, D., \& Engquist, G. (1976). The perceptual organization of ongoing behavior. Journal of Experimental Social Psychology, 12, 436450. doi:10.1016/0022-1031(76)90076-7

The New Yorker. (1976, March 29). [Magazine cover]. Retrieved July, 5,
2014, from http://en.wikipedia.org/wiki/View_of_the_World_ from_9th_Avenue

Nigro, G., \& Neisser, U. (1983). Point of view in personal memories. Cognitive Psychology, 15, 467-482. doi:10.1016/0010-0285(83)90016-6

O'Keefe, J., \& Dostrovsky, J. (1971). The hippocampus as a spatial map. Preliminary evidence from unit activity in the freely-moving rat. Brain Research, 34, 171-175. doi:10.1016/0006-8993(71)90358-1

O'Keefe, J., \& Nadel, L. (1978). The hippocampus as a cognitive map (Vol. 3). Oxford, England: Clarendon Press.

Palombo, D. J., Williams, L. J., Abdi, H., \& Levine, B. (2013). The Survey of Autobiographical Memory (SAM): A novel measure of trait mnemonics in everyday life. Cortex, 49, 1526-1540. doi:10.1016/j.cortex 2012.08.023

Park, S., \& Chun, M. M. (2009). Different roles of the parahippocampal place area (PPA) and retrosplenial cortex (RSC) in panoramic scene perception. NeuroImage, 47, 1747-1756. doi:10.1016/j.neuroimage .2009.04.058

Piolino, P., Desgranges, B., Clarys, D., Guillery-Girard, B., Tacconat, L., Isingrini, M., \& Eustache, F. (2006). Autobiographical memory, autonoetic consciousness, and self-perspective in aging. Psychology and Aging, 21, 510-525. doi:10.1037/0882-7974.21.3.510

Piolino, P., Desgranges, B., \& Eustache, F. (2009). Episodic autobiographical memories over the course of time: Cognitive, neuropsychological and neuroimaging findings. Neuropsychologia, 47, 2314-2329. doi: 10.1016/j.neuropsychologia.2009.01.020

Posner, M. J., \& Keele, S. (1970). Retention of abstract ideas. Journal of Experimental Psychology, 83, 304-308. doi:10.1037/h0028558

Puce, A., Allison, T., Gore, J. C., \& McCarthy, G. (1995). Face-sensitive regions in human extrastriate cortex studied by functional MRI. Journal of Neurophysiology, 74, 1192-1199.

Race, E., Keane, M. M., \& Verfaellie, M. (2011). Medial temporal lobe damage causes deficits in episodic memory and episodic future thinking not attributable to deficits in narrative construction. Journal of Neuroscience, 31, 10262-10269. doi:10.1523/JNEUROSCI.1145-11.2011

Raffard, S., D'Argembeau, A., Bayard, S., Boulenger, J.-P., \& Van der Linden, M. (2010). Scene construction in schizophrenia. Neuropsychology, 24, 608-615. doi:10.1037/a0019113

Rasmussen, K. W. (2013). The role of the hippocampus and prefrontal cortex in imagining the future: Insights from studies of patients with focal brain lesions. Nordic Psychology, 65, 166-188. doi:10.1080/ 19012276.2013.807666

Ratcliff, R., \& McKoon, G. (1986). More on the distinction between episodic and semantic memories. Journal of Experimental Psychology: Learning, Memory, and Cognition, 12, 312-313. doi:10.1037/0278-7393 .12 .2 .312

Reed, J. M., \& Squire, L. R. (1998). Retrograde amnesia for facts and events: Findings from four new cases. Journal of Neuroscience, 18, 3943-3954

Renoult, L., Davidson, P. S. R., Palombo, D. J., Moscovitch, M., \& Levine, B. (2012). Personal semantics: At the crossroads of semantic and episodic memory. Trends in Cognitive Sciences, 16, 550-558. doi:10.1016/ j.tics.2012.09.003

Rice, H. J. (2010). Seeing where we're at: A review of visual perspective and memory retrieval. In J. H. Mace (Ed.), The act of remembering: Toward an understanding of how we recall the past (pp. 228-258). Chichester, England: Wiley-Blackwell. doi:10.1002/9781444328202 .ch10

Rice, H. J., \& Rubin, D. C. (2011). Remembering from any angle: The flexibility of visual perspective during retrieval. Consciousness and Cognition, 20, 568-577. doi:10.1016/j.concog.2010.10.013

Rifkin, A. (1985). Evidence for a basic level in event taxonomies. Memory \& Cognition, 13, 538-556. doi:10.3758/BF03198325 
Roediger, H. L., III. (1984). Does current evidence from dissociation experiments favor the episodic/semantic distinction? Behavioral and Brain Sciences, 7, 252-254. doi:10.1017/S0140525X00044563

Roediger, H. L., III, Buckner, R. L., \& McDermott, K. B. (1999). Components of processing. In J. K. Foster \& M. Jelicic (Eds.), Memory: Systems, process or function? (pp. 31-65). Oxford, England: Oxford University Press. doi:10.1093/acprof:oso/9780198524069.003.0003

Rosch, E., Mervis, C. B., Gray, W. D., Johnson, D. M., \& Boyes-Braem, P. (1976). Basic objects in natural categories. Cognitive Psychology, 8, 382-439. doi:10.1016/0010-0285(76)90013-X

Rosenbaum, R. S., Gilboa, A., Levine, B., Winocur, G., \& Moscovitch, M. (2009). Amnesia as an impairment of detail generation and binding: Evidence from personal, fictional, and semantic narratives in K. C. Neuropsychologia, 47, 2181-2187. doi:10.1016/j.neuropsychologia .2008 .11 .028

Rosenbaum, R. S., Priselac, S., Köhler, S., Black, S. E., Gao, F., Nadel, L., $\&$ Moscovitch, M. (2000). Remote spatial memory in an amnesic person with extensive bilateral hippocampal lesions. Nature Neuroscience, 3, 1044-1048. doi:10.1038/79867

Rosenbaum, R. S., Winocur, G., \& Moscovitch, M. (2001). New views on old memories: Re-evaluating the role of the hippocampal complex. Behavioural Brain Research, 127, 183-197. doi:10.1016/S01664328(01)00363-1

Rosenbaum, R. S., Ziegler, M., Winocur, G., Grady, C. L., \& Moscovitch, M. (2004). "I have often walked down this street before": fMRI studies on the hippocampus and other structures during mental navigation of an old environment. Hippocampus, 14, 826-835. doi:10.1002/hipo.10218

Rubin, D. C. (1988). Go for the skill. In U. Neisser \& E. Winograd (Eds.), Remembering reconsidered: Ecological and traditional approaches to the study of memory (pp. 374-382). Cambridge, England: Cambridge University Press. doi:10.1017/CBO9780511664014.016

Rubin, D. C. (1995). Memory in oral traditions: The cognitive psychology of epic, ballads, and counting-out rhymes. New York, NY: Oxford University Press.

Rubin, D. C. (2006). The basic-systems model of episodic memory. Perspectives on Psychological Science, 1, 277-311. doi:10.1111/j.17456916.2006.00017.x

Rubin, D. C. (2012). The basic systems model of autobiographical memory. In D. Berntsen \& D. C. Rubin (Eds.), Understanding autobiographical memory: Theories and approaches (pp. 11-32). Cambridge, England: Cambridge University Press. doi:10.1017/CBO9781139021937 .004

Rubin, D. C. (2014). Schema-driven construction of future autobiographical traumatic events: The future is much more troubling than the past. Journal of Experimental Psychology: General, 143, 612-630. doi: 10.1037/a0032638

Rubin, D. C., \& Baddeley, A. (1989). Telescoping is not time compression: A model of the dating of autobiographical events. Memory \& Cognition, 17, 653-661. doi:10.3758/BF03202626

Rubin, D. C., \& Berntsen, D. (2009). The frequency of voluntary and involuntary autobiographical memories across the lifespan. Memory \& Cognition, 37, 679-688. doi:10.3758/37.5.679

Rubin, D. C., Berntsen, D., \& Hutson, M. (2009). The normative and the personal life: Individual differences in life scripts and life stories among USA and Danish undergraduates. Memory, 17, 54-68. doi:10.1080/ 09658210802541442

Rubin, D. C., Boals, A., \& Berntsen, D. (2008). Memory in posttraumatic stress disorder: Properties of voluntary and involuntary, traumatic and nontraumatic autobiographical memories in people with and without posttraumatic stress disorder symptoms. Journal of Experimental Psychology: General, 137, 591-614. doi:10.1037/a0013165

Rubin, D. C., Burt, C. D. B., \& Fifield, S. J. (2003). Experimental manipulations of the phenomenology of memory. Memory \& Cognition, 31, 877-886. doi:10.3758/BF03196442
Rubin, D. C., Dennis, M., \& Beckham, J. (2011). Autobiographical memory for stressful events: The role of autobiographical memory in posttraumatic stress disorder. Consciousness and Cognition, 20, 840-856. doi:10.1016/j.concog.2011.03.015

Rubin, D. C., \& Greenberg, D. L. (1998). Visual memory-deficit amnesia: A distinct amnesic presentation and etiology. Proceedings of the National Academy of Sciences of the United States of America, 95, 54135416. doi:10.1073/pnas.95.9.5413

Rubin, D. C., \& Greenberg, D. L. (2003). The role of narrative in recollection: A view from cognitive psychology and neuropsychology. In G. D. Fireman, T. E. McVay Jr., \& O. J. Flanagan (Eds.), Narrative and consciousness: Literature, psychology, and the brain (pp. 53-85). New York, NY: Oxford University Press. doi:10.1093/acprof:oso/ 9780195140057.003.0004

Rubin, D. C., \& Kozin, M. (1984). Vivid memories. Cognition, 16, 81-95. doi:10.1016/0010-0277(84)90037-4

Rubin, D. C., Schrauf, R. R. W., \& Greenberg, D. L. (2003). Belief and recollection of autobiographical memories. Memory \& Cognition, 31, 887-901. doi:10.3758/BF03196443

Rubin, D. C., Schrauf, R. W., Gulgoz, S., \& Naka, M. (2007). Crosscultural variability of component processes in autobiographical remembering: Japan, Turkey, and the USA. Memory, 15, 536-547. doi: 10.1080/09658210701332679

Rubin, D. C., \& Siegler, I. C. (2004). Facets of personality and the phenomenology of autobiographical memory. Applied Cognitive Psychology, 18, 913-930. doi:10.1002/acp.1038

Salwiczek, L. H., Watanabe, A., \& Clayton, N. S. (2010). Ten years of research into avian models of episodic-like memory and its implications for developmental and comparative cognition. Behavioural Brain Research, 215, 221-234. doi:10.1016/j.bbr.2010.06.011

Schacter, D. L., \& Addis, D. R. (2007). The cognitive neuroscience of constructive memory: Remembering the past and imagining the future. Philosophical Transactions of the Royal Society B: Biological Sciences, 362, 773-786. doi:10.1098/rstb.2007.2087

Schacter, D. L., \& Addis, D. R. (2009). On the nature of medial temporal lobe contributions to the constructive simulation of future events. Philosophical Transactions of the Royal Society B: Biological Sciences, 364, 1245-1253. doi:10.1098/rstb.2008.0308

Schacter, D. L., Addis, D. R., \& Buckner, R. L. (2007). Remembering the past to imagine the future: The prospective brain. Nature Reviews Neuroscience, 8, 657-661. doi:10.1038/nrn2213

Scoville, W. B., \& Milner, B. (1957). Loss of recent memory after bilateral hippocampal lesions. Journal of Neurology, Neurosurgery, \& Psychiatry, 20, 11-21. doi:10.1136/jnnp.20.1.11

Sheen, M., Kemp, S., \& Rubin, D. C. (2001). Twins dispute memory ownership: A new false memory phenomenon. Memory \& Cognition, 29, 779-788. doi:10.3758/BF03196407

Shoben, E. J., Wescourt, K. T., \& Smith, E. E. (1978). Sentence verification, sentence recognition, and the semantic-episodic distinction. Journal of Experimental Psychology: Human Learning and Memory, 4, 304-317. doi:10.1037/0278-7393.4.4.304

Skinner, B. F. (1972). A lecture on "having" a poem. In B. F. Skinner (Ed.), Cumulative record: A selection of papers (3rd ed., pp. 345-355). New York, NY: Appleton Century Crofts.

Smith, D. M., \& Mizumori, S. J. (2006). Hippocampal place cells, context, and episodic memory. Hippocampus, 16, 716-729. doi:10.1002/hipo .20208

Spreng, R. N., Mar, R. A., \& Kim, A. S. N. (2009). The common neural basis of autobiographical memory, prospection, navigation, theory of mind, and the default mode: A quantitative meta-analysis. Journal of Cognitive Neuroscience, 21, 489-510. doi:10.1162/jocn.2008.21029

Squire, L. R. (1992). Memory and the hippocampal region: A synthesis of findings with rats, monkeys, and humans. Psychological Review, 99, 195-231. doi:10.1037/0033-295X.99.2.195 
Squire, L. R., \& Alvarez, P. (1995). Retrograde amnesia and memory consolidation: A neurobiological perspective. Current Opinion in Neurobiology, 5, 169-177. doi:10.1016/0959-4388(95)80023-9

Squire, L. R., van der Horst, A. S., McDuff, S. G., Frascino, J. C., Hopkins, R. O., \& Mauldin, K. N. (2010). Role of the hippocampus in remembering the past and imagining the future. Proceedings of the National Academy of Sciences of the United States of America, 107, 1904419048. doi:10.1073/pnas.1014391107

Squire, L. R., \& Wixted, J. T. (2011). The cognitive neuroscience of human memory since H. M. Annual Review of Neuroscience, 34, 259-288. doi:10.1146/annurev-neuro-061010-113720

Squire, L. R., \& Zola, S. M. (1998). Episodic memory, semantic memory, and amnesia. Hippocampus, 8, 205-211. doi:10.1002/(SICI)10981063(1998)8:3<205::AID-HIPO3>3.0.CO;2-I

St. Jacques, P. L. (2012). Functional neuroimaging of autobiographical memory. In D. Berntsen \& D. C. Rubin. (Eds.), Understanding autobiographical memory: Theories and approaches (pp. 114-138). Cambridge, England: Cambridge University Press. doi:10.1017/ CBO9781139021937.010

St. Jacques, P. L., Rubin, D. C., \& Cabeza, R. (2012). Age-related effects on the neural correlates of autobiographical memory retrieval. Neurobiology of Aging, 33, 1298-1310. doi:10.1016/j.neurobiolaging.2010.11 .007

St. Jacques, P., Rubin, D. C., LaBar, K. S., \& Cabeza, R. (2008). The short and long of it: Neural correlates of temporal-order memory for autobiographical events. Journal of Cognitive Neuroscience, 20, 1327-1341. doi:10.1162/jocn.2008.20091

Suzuki, W. A., \& Clayton, N. S. (2000). The hippocampus and memory: A comparative and ethological perspective. Current Opinion in Neurobiology, 10, 768-773. doi:10.1016/S0959-4388(00)00148-3

Szpunar, K. K. (2010). Episodic future thought: An emerging concept. Perspectives on Psychological Science, 5, 142-162. doi:10.1177/ 1745691610362350

Szpunar, K. K., Watson, J. M., \& McDermott, K. B. (2007). Neural substrates of envisioning the future. Proceedings of the National Academy of Sciences of the United States of America, 104, 642-647. doi: 10.1073/pnas.0610082104

Teng, E., \& Squire, L. R. (1999). Memory for places learned long ago is intact after hippocampal damage. Nature, 400, 675-677. doi:10.1038/ 23276

Thomsen, D. K. (2009). There is more to life stories than memories. Memory, 17, 445-457. doi:10.1080/09658210902740878

Thomsen, D. K., Olesen, M. H., Schnieber, A., Jensen, T., \& Tønnesvang, J. (2012). What characterizes life story memories? A diary study of Freshmen's first term. Consciousness and Cognition, 21, 366-382. doi:10.1016/j.concog.2012.01.006

Tiberghien, G. (1984). Just how does ecphory work? Behavioral and Brain Sciences, 7, 255-256. doi:10.1017/S0140525X00044599

Tolman, E. C. (1948). Cognitive maps in rats and men. Psychological Review, 55, 189-208. doi:10.1037/h0061626

Toth, J. P., \& Hunt, R. R. (1999). Not one versus many, but zero versus any: Structure and function in the context of the multiple memory systems debate. In J. K. Foster \& M. Jelicic (Eds.), Memory: Systems, process or function? (pp. 232-272). New York, NY: Oxford University Press. doi:10.1093/acprof:oso/9780198524069.003.0009

Tulving, E. (1972). Episodic and semantic memory. In E. Tulving \& W. Donaldson (Eds.), Organization of memory (pp. 381-402). New York, NY: Academic Press.

Tulving, E. (1983). Elements of episodic memory. Oxford, England: Clarendon Press.

Tulving, E. (1984). Précis of elements of episodic memory. Behavioral and Brain Sciences, 7, 223-268. doi:10.1017/S0140525X0004440X

Tulving, E. (1985). Memory and consciousness. Canadian Psychology, 26, 1-12. doi:10.1037/h0080017
Tulving, E. (1986). What kind of a hypothesis is the distinction between episodic and semantic memory? Journal of Experimental Psychology: Learning, Memory, and Cognition, 12, 307-311. doi:10.1037/0278-7393 .12 .2 .307

Tulving, E. (2002). Episodic memory: From mind to brain. Annual Review of Psychology, 53, 1-25. doi:10.1146/annurev.psych.53 .100901 .135114

Tversky, B. (1993). Cognitive maps, cognitive collages, and spatial mental models. In A. U. Frank \& I. Campari (Eds.), Spatial information theory: A theoretical basis for GIS (pp. 14-24). Berlin, Germany: SpringerVerlag. doi:10.1007/3-540-57207-4_2

Tversky, B., \& Hemenway, K. (1983). Categories of environmental scenes. Cognitive Psychology, 15, 121-149. doi:10.1016/0010-0285(83) 90006-3

Umanath, S., \& Marsh, E. J. (2014). Understanding how prior knowledge influences memory in older adults. Perspectives on Psychological Science, 9, 408-426. doi:10.1177/1745691614535933

Wais, P. E., Mickes, L., \& Wixted, J. T. (2008). Remember/know judgments probe degrees of recollection. Journal of Cognitive Neuroscience, 20, 400-405. doi:10.1162/jocn.2008.20041

Watkins, M. J., \& Kerkar, S. P. (1985). Recall of a twice-presented item without recall of either presentation: Generic memory for events. Journal of Memory and Language, 24, 666-678. doi:10.1016/0749596X(85)90052-X

Watson, M. E., \& Rubin, D. C. (1996). Spatial imagery preserves temporal order. Memory, 4, 515-534. doi:10.1080/741940777

Wheeler, M. A., Stuss, D. T., \& Tulving, E. (1997). Toward a theory of episodic memory: The frontal lobes and autonoetic consciousness. Psychological Bulletin, 121, 331-354. doi:10.1037/0033-2909.121.3 .331

Williams, J. M. G. (1996). Depression and the specificity of autobiographical memory. In D. C. Rubin (Ed.), Remembering our past: Studies in autobiographical memory (pp. 244-268). Cambridge, England: Cambridge University Press doi:10.1017/CBO9780511527913.010

Williams, J. M. G., Barnhofer, T., Crane, C., Herman, D., Raes, F., Watkins, E., \& Dalgleish, T. (2007). Autobiographical memory specificity and emotional disorder. Psychological Bulletin, 133, 122-148. doi:10.1037/0033-2909.133.1.122

Winocur, G., \& Moscovitch, M. (2011). Memory transformation and systems consolidation. Journal of the International Neuropsychological Society, 17, 766-780. doi:10.1017/S1355617711000683

Winocur, G., Moscovitch, M., \& Bontempi, B. (2010). Memory formation and long-term retention in humans and animals: Convergence towards a transformation account of hippocampal-neocortical interactions. Neuropsychologia, 48, 2339-2356. doi:10.1016/j.neuropsychologia.2010.04 .016

Winocur, G., Moscovitch, M., Fogel, S., Rosenbaum, R. S., \& Sekeres, M. (2005). Preserved spatial memory after hippocampal lesions: Effects of extensive experience in a complex environment. Nature Neuroscience, 8, 273-275. doi:10.1038/nn1401

Wixted, J. T., \& Mickes, L. (2010). A continuous dual-process model of remember/know judgments. Psychological Review, 117, 1025-1054. doi: $10.1037 / \mathrm{a} 0020874$

Wolters, G. (1984). Memory: Two systems or one system with many subsystems? Behavioral and Brain Sciences, 7, 256-257. doi:10.1017/ S0140525X00044605

Wood, E. R., Dudchenko, P. A., \& Eichenbaum, H. (1999). The global record of memory in hippocampal neuronal activity. Nature, 397, 613 616. doi:10.1038/17605

Worden, R. (1992). Navigation by fragment fitting: A theory of hippocampal function. Hippocampus, 2, 165-187. doi:10.1002/hipo.450020208

Yonelinas, A. P. (2013). The hippocampus supports high-resolution binding in the service of perception, working memory and long-term 
memory. Behavioural Brain Research. doi:10.1016/j.bbr.2013.05 .030

Zacks, J. M., Speer, N. K., Swallow, K. M., Braver, T. S., \& Reynolds, J. R. (2007). Event perception: A mind-brain perspective. Psychological Bulletin, 133, 273-293. doi:10.1037/0033-2909.133.2.273

Zacks, J. M., \& Swallow, K. M. (2007). Event segmentation. Current Directions in Psychological Science, 16, 80-84. doi:10.1111/j.14678721.2007.00480.x
Zacks, J. M., \& Tversky, B. (2001). Event structure in perception and conception. Psychological Bulletin, 127, 3-21. doi:10.1037/0033-2909 .127 .1 .3

Received November 10, 2013 Revision received August 6, 2014 Accepted August 13, 2014

\section{ORDER FORM}

Start my 2015 subscription to Psychological Review ${ }^{\circledR}$ ISSN: 0033-295X

$\$ 99.00$

APA MEMBER/AFFILIATE

$\$ 229.00$

INDIVIDUAL NONMEMBER

$\$ 899.00$

\section{INSTITUTION}

Sales Tax: $5.75 \%$ in DC and $6 \%$ in MD

TOTAL AMOUNT DUE

Subscription orders must be prepaid. Subscriptions are on a calendar year basis only. Allow 4-6 weeks for delivery of the first issue. Call for international subscription rates.

\section{SEND THIS ORDER FORM TO}

American Psychological Association

Subscriptions

750 First Street, NE

Washington, DC 20002-4242

AMERICAN PSYCHOLOGICAL ASSOCIATION

Call 800-374-2721 or 202-336-5600

Fax 202-336-5568 :TDD/TTY 202-336-6123

For subscription information,

e-mail: subscriptions@apa.org $\square$ Check enclosed (make payable to APA)

Charge my: $\square$ Visa $\square$ MasterCard $\square$ American Express

Cardholder Name

Card No. _ Exp. Date

Signature (Required for Charge)

\section{Billing Address}

Street

City State Zip

Daytime Phone

E-mail

Mail To

Name

Address

City State

Zip 